\title{
Recent Developments in the Chemistry of Heteroaromatic $\mathrm{N}$-Oxides
}

\author{
Youliang Wang \\ Liming Zhang*
}

Department of Chemistry and Biochemistry, University of California, Santa Barbara, CA 93106, USA zhang@chem.ucsb.edu

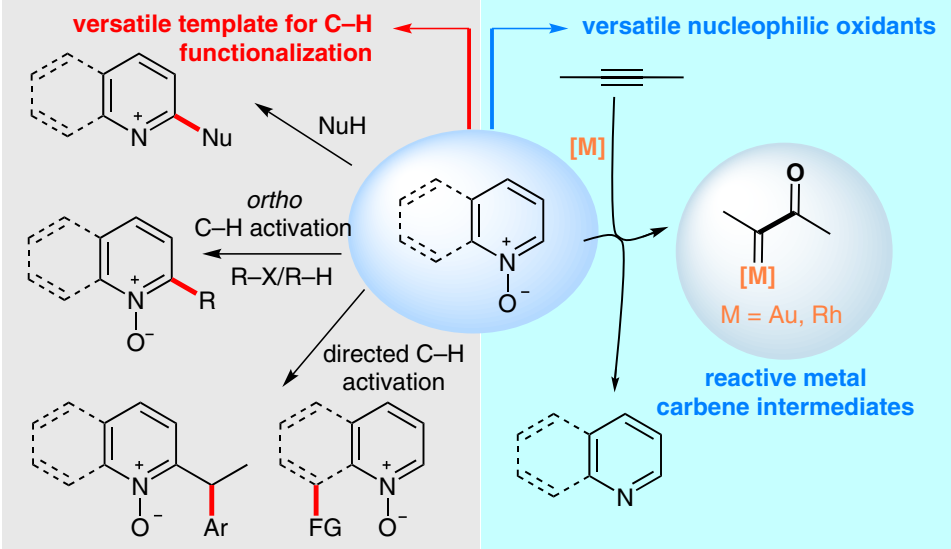

Received: 01.09.2014

Accepted after revision: 23.10.2014

Published online: 14.01 .2015

DOI: 10.1055/s-0034-1379884; Art ID: ss-2014-e0541-r

Abstract Selected developments in the chemistry of heteroaromatic $\mathrm{N}$-oxides since 2001 are presented in this review. The use of these $\mathrm{N}$ oxides, both in late-transition-metal-catalyzed oxidations of carboncarbon triple bonds and in regioselective $\mathrm{C}-\mathrm{H}$ functionalizations of the heteroarene, are contemporary topics of interest and the focus of the discussion.

1 Introduction

2 Synthesis of Heteroaromatic $\mathrm{N}$-Oxides

2.1 Direct Oxidation of Hindered Heteroarenes

2.2 Through Construction of Heteroaromatic Rings

3 Heteroaromatic $\mathrm{N}$-Oxides as Oxidants

3.1 Alkyne Oxidation

3.2 Allene Oxidation

3.3 Carbene Oxidation

4 Heteroaromatic $\mathrm{N}$-Oxides as Substrates

4.1 Deoxygenative ortho-C-H Functionalization with Prior Activation

4.2 Deoxygenative ortho- $\mathrm{C}-\mathrm{H}$ Functionalization with Nonstabilized Carbanions

4.3 Nondeoxygenative $\mathrm{C}-\mathrm{H}$ Functionalization

4.3.1 ortho-C-H Functionalization

4.3.2 N-Oxide Directed ortho-Alkyl C-H Functionalization

4.3.3 N-Oxide Directed Remote C-H Functionalization

4.4 1,3-Dipolar Cycloaddition

5 Conclusion and Outlook

Key words oxidations, alkynes, cycloadditions, carbenes, pyridines

\section{Introduction}

Heteroaromatic $\mathrm{N}$-oxides possess a 1,2-dipolar nitrogen-oxygen bond, where the nitrogen atom is part of the heteroaromatic ring. The formally negatively charged oxygen has a substantial impact on the physical properties and reactivities of the arene ring, which can be mostly rationalized by electron delocalization. Scheme 1 depicts the important canonical forms of pyridine $\mathrm{N}$-oxide, which along with its congeners represents a synthetically versatile subset of heteroaromatic $\mathrm{N}$-oxides and will be the focus of this review. For the typically drawn dipolar structure $\mathbf{A}$, the positive charge on nitrogen can delocalize to the ortho positions as in the resonance structures of $\mathbf{B}$ and $\mathbf{C}$ and the para position as in $\mathbf{D}$, therefore rendering those sites electrophilic and susceptible toward nucleophilic attack; consequently, electron-donating substituents at these sites enhance the contribution of these canonical forms to the overall stability of the $\mathrm{N}$-oxide and increase the nucleophilicity of the negatively charged oxygen. Alternatively, the negative charge on the oxygen atom can delocalize into the pyridine ring, thereby generating the resonance structures $\mathbf{E}, \mathbf{F}$ and $\mathbf{G}$ and rendering the very same sites on the pyridine ring discussed above nucleophilic and reactive in electrophilic aromatic substitutions. The relatively short $\mathrm{N}-\mathrm{O}$ bond $(1.28 \AA$, compared to the $1.383 \AA$ observed in $N$-methylmorpholine $\mathrm{N}$-oxide ${ }^{1}$ ) and the much smaller increase of dipole moment over pyridine (2.02D) than that of trimethylamine $\mathrm{N}$-oxide (4.37D) are indicative of the contribution of these canonical forms. As a consequence, electron-withdrawing substituents also stabilize pyridine $N$-oxides, thereby permitting their ready preparation.

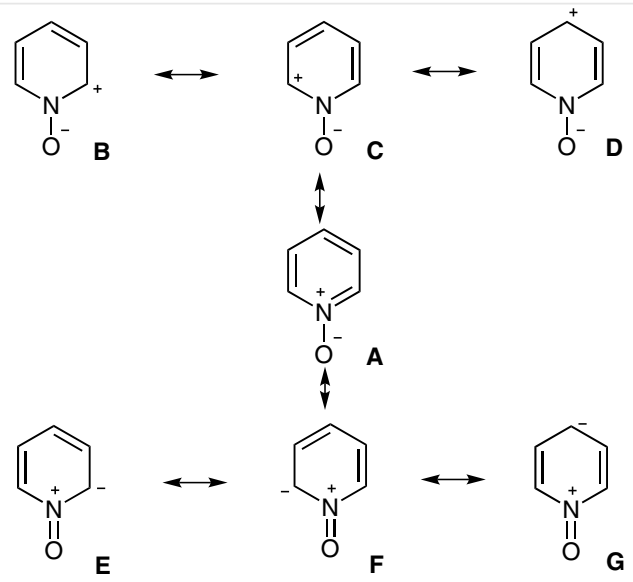

Scheme 1 Canonical forms of pyridine $\mathrm{N}$-oxide 
The negatively charged oxygen, besides impacting the heteroarene electronically, offers a versatile nucleophilic oxidation site and enables directed $\mathrm{C}-\mathrm{H}$ functionalizations.

Pyridine $N$-oxides are weak bases and less basic than the corresponding pyridines. The $\mathrm{p} K_{\mathrm{a}}$ values of the conjugate acids of pyridine $N$-oxides in water are around $1.0 .^{2}$ In contrast, the conjugate acids of the corresponding pyridines have $\mathrm{p} K_{\mathrm{a}}$ values around 5 . This phenomenon is attributed to the solvation effect, as there is little difference in their basicity in the gas phase. ${ }^{3}$

A monograph ${ }^{3}$ in 1991 and a review ${ }^{4}$ in 2001 elegantly summarized the properties and reactivities of heteroaromatic $N$-oxides. In this review, we limit the literature coverage to selected and representative developments in the chemistry of heteroaromatic $N$-oxides since 2001 and focus mostly on versatile metal-catalyzed oxidations of alkynes using them as oxidants, and their $\mathrm{C}-\mathrm{H}$ functionalization reactions, both of which have been among the intensely studied areas of contemporary organic chemistry.

\section{Synthesis of Heteroaromatic $\mathbf{N}$-Oxides}

\subsection{Direct Oxidation of Hindered Heteroarenes}

Direct oxidation of heteroarenes to heteroaromatic $N$ oxides can be realized with strong oxidants such as $m$ choroperoxybenzoic acid, ${ }^{5}$ magnesium monoperphthalate, ${ }^{6}$ in situ generated percarboxylic acids ${ }^{7}$ and dimethyldioxirane (DMDO). ${ }^{8} \mathrm{~A}$ common problem with the often-used $\mathrm{m}$ choroperoxybenzoic acid is the difficulty of removing the byproduct $m$-chlorobenzoic acid, which results in decreased isolated yields. Sharpless and co-workers developed a generally preferred methyltrioxorhenium-catalyzed oxidation using hydrogen peroxide as the stoichiometric oxidant. ${ }^{9}$ While this method is often highly efficient for unhindered pyridines and quinolines, it appears to be sensitive to steric hindrance and does not work well with pyridines containing 2-substitutents, except for a small methyl or cyano group.

The oxidation of 1,10-phenanthroline into its $N, N^{\prime}$-dioxide is extremely challenging owing to the necessity of twisting the tricyclic ring system out of planarity in order to accommodate the two anionic oxygen atoms; hence, it was not achieved with either m-choroperoxybenzoic acid or dimethyldioxirane. However, HOF.MeCN, perhaps the best oxygen-transfer agent and easily accessible from fluorine gas (commercially available as a mixture with an inert gas) and aqueous acetonitrile, readily accomplished this and related transformations in two minutes and with fair to good yields (Equation 1). This method offers a potential solution to the oxidation of other highly hindered substrates. ${ }^{10}$
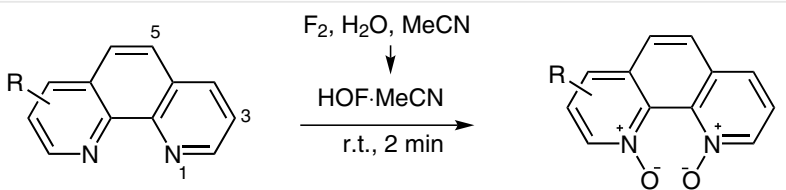

$\mathrm{R}=\mathrm{H}, 60 \%$

$\mathrm{R}=4-\mathrm{Ph}, 74 \%$

$\mathrm{R}=5-\mathrm{Cl}, 67 \%$

$\mathrm{R}=3,4-\mathrm{Me}_{2}, 67 \%$

Equation 1

\section{Biographical Sketches}

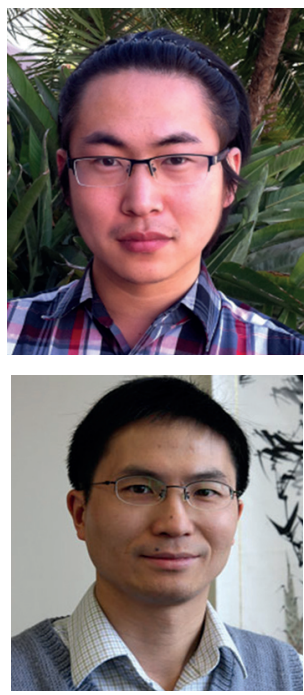

Youliang Wang was born in Shandong, P. R. of China, in 1989. He received his B.S. degree in 2011 from the University of Science and Technology of China where he conducted

Liming Zhang was born in Pingxiang, P. R. of China, in 1972. He received his B.S. degree in chemistry from Nanchang University in 1993, his first Master's degree in organometallic chemistry from Nankai University in 1996, and his second Master's degree in organic chemistry from the University of Alabama with Professor undergraduate research under the direction of Professor GuanWu Wang. In the same year, he started his doctoral studies at the University of California Santa Barbara under the direc-

Michael P. Cava in 1998. He obtained his Ph.D. with Professor Masato Koreeda from the medicinal chemistry program at the University of Michigan in 2003 and then carried out a postdoctoral study with professor Sergey A. Kozmin at the University of Chicago. He started his independent academic career as Assistant Professor in the tion of Professor Liming Zhang. His current research interest is gold-catalyzed oxidative transformations of alkynes.

Department of Chemistry at the University of Nevada, Reno in 2005 and continued at the University of California - Santa Barbara in 2009. His research interests include reactions catalyzed by late transition metals, natural product synthesis and medicinal chemistry. 


\subsection{Through Construction of Heteroaromatic Rings}

$\mathrm{N}$-Heteroarene $\mathrm{N}$-oxides can also be prepared from substrates with pre-existing nitrogen-oxygen bonds via the construction of the arene ring. For example, a direct preparation of isoquinoline $\mathrm{N}$-oxides from ortho-alkynylbenzaldoximes was realized by the use of alkynophilic catalysts such as cationic gold(I) complexes or simple silver triflate (Equation 2). ${ }^{11}$ A gold-catalyzed [3+3] cycloaddition between nitrosobenzene and a $\beta, \gamma$-unsaturated $\alpha$-diazo ester offers a modular access to quinoline $\mathrm{N}$-oxides, which entails the generation of a capto-dative gold carbene, its regioselective nitrogen-trapping by nitrosobenzene, electrocyclic ring closure and dehydrogenative aromatization (Scheme $2)^{12} \mathrm{~A}$ rhodium(III)-catalyzed annulation between an oxime and an $\alpha$-diazo- $\beta$-keto ester or diketone offers modular access to multi-substituted isoquinoline and pyridine $\mathrm{N}$-oxides (Scheme 3). ${ }^{13}$ Mechanistically, the reaction is proposed to undergo tandem rhodium-mediated $\mathrm{C}-\mathrm{H}$ activation, carbene insertion and cyclization.

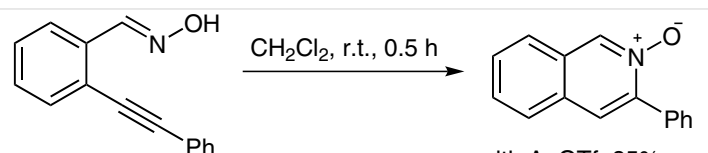

with AgOTf, 85\% with $\mathrm{Au}$ (IMes)OTf, 96\%

Equation 2

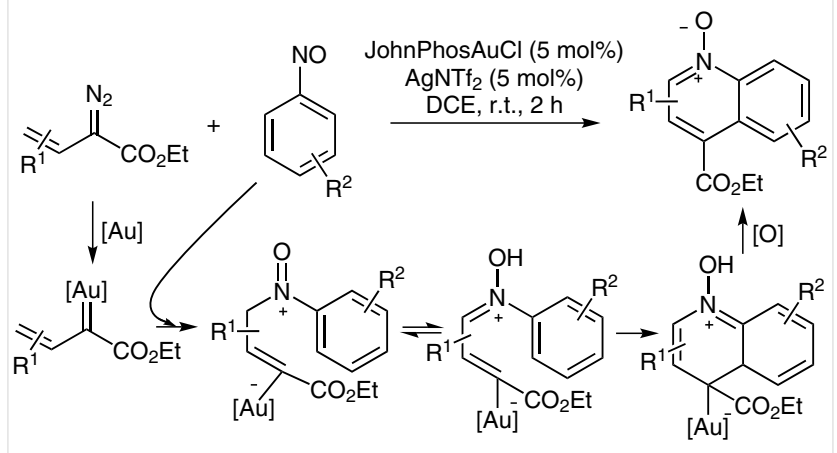<smiles>CCOC(=O)c1cc[n+]([O-])c2ccccc12</smiles>

$72 \%$

$72 \%$

$77 \%$

$68 \%$

Scheme 2

As direct oxidations ${ }^{14}$ of imidazole compounds into their $\mathrm{N}$-oxides have met with limited success, ${ }^{5}$ this type of oxide can be readily prepared by way of the condensation between $\alpha$-keto oximes and imines. ${ }^{15}$ Scheme 4 outlines a highly efficient example where the understood reaction mechanism includes the imine part, methylimine, being generated in situ from 1,3,5-trimethyltriazinane. ${ }^{15 c}$

Scheme 3

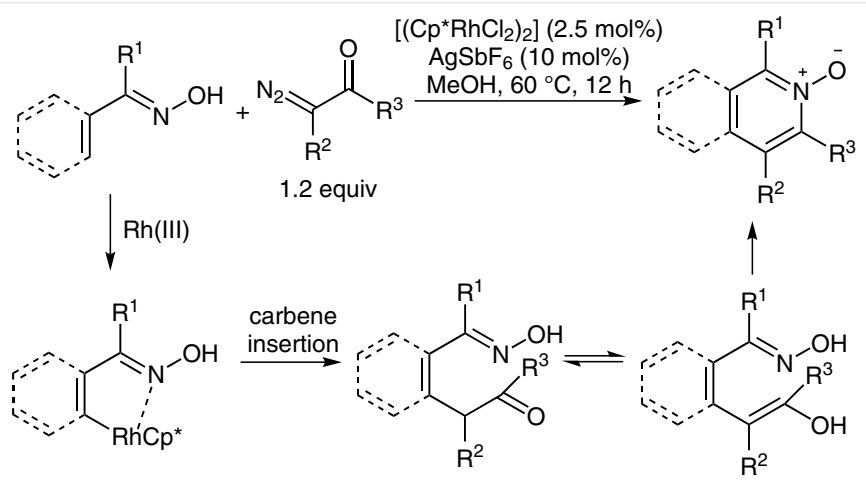<smiles>CCOC(=O)c1c(C)[n+]([O-])cc2ccccc12</smiles>

$\mathrm{R}=\mathrm{H}, 99 \%$

$\mathrm{R}=3-\mathrm{Me}, 58 \%$ $\mathrm{R}=1-\mathrm{F}, 58 \%$<smiles>CCOC(=O)c1c(-c2ccccc2)cc([N+](=O)[O-])[n+]([O-])c1C</smiles>

$42 \%$<smiles>CCOC(=O)c1cc(OC)c([N+](=O)[O-])[n+]([O-])c1</smiles>

$72 \%$<smiles>CCOC(=O)c1c2c(c([N+]([O-])[O-])[n+](C)c1CC)CCCC2</smiles>

$80 \%$ 


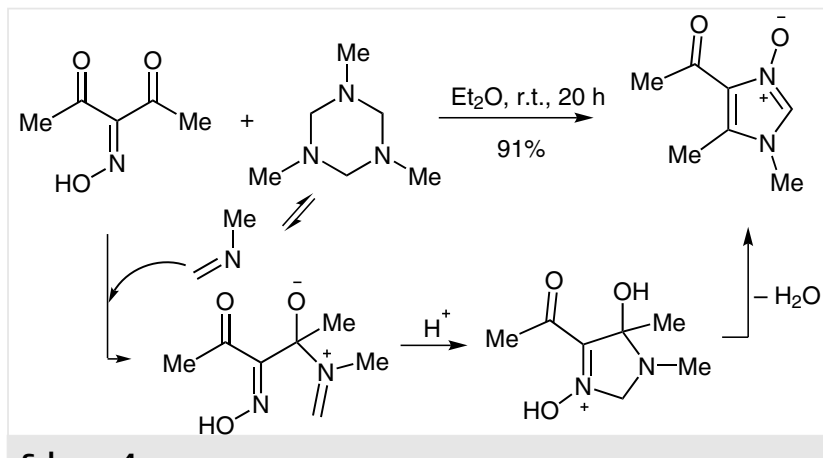

Scheme 4

Through a mechanistically similar strategy, oxazole $\mathrm{N}$ oxides such as $\mathbf{1}^{16}$ were prepared from $\alpha$-keto oximes and aldehydes under acidic conditions (Equation 3). ${ }^{16,17}$<smiles>CC(=O)/C(=N/O)C(=O)OCc1cccc(F)c1</smiles>

Equation 3

\section{Heteroaromatic $\mathrm{N}$-Oxides as Oxidants}

As reagents, heteroarene $\mathrm{N}$-oxides are versatile and yet mild nucleophilic oxidants that can effect a diverse range of powerful oxidative transformations mostly in the presence of metal catalysts. Two features make them unique: 1) their oxygen atoms possess sufficient nucleophilicity due to their negatively charged nature and minimal steric size, yet they are nearly non-basic (vide supra); and 2) the nitrogen-oxygen bond is weak, with a bond dissociation energy of 63.3 $\mathrm{kcal} / \mathrm{mol}$ for pyridine $\mathrm{N}$-oxide, ${ }^{18}$ and therefore prone to heterolytic fragmentation. This fragmentation follows an initial nucleophilic attack by the oxygen atom. The net result of this two-step sequence is nucleophilic oxidation, which manifests two distinct scenarios: 1 ) $\mathrm{N}$-oxides form covalent bonds with substrates and are intimately involved in their conversions into products; and 2) they oxidize metal catalysts into corresponding higher-valence metal oxides, which then carry out the intended substrate transformations (Scheme 5). The discussion in this section focuses on the first scenario as the reactivities tend to be unique to these heteroarene $\mathrm{N}$-oxides. In contrast, the second scenario does not engage direct interactions between substrates and oxidants; as a result, heteroaromatic $\mathrm{N}$-oxides can be just one of various types of effective oxidants.

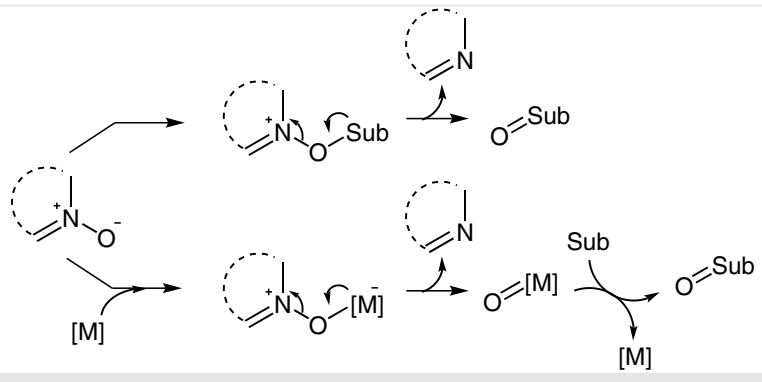

Scheme 5

Among the heteroaromatic $N$-oxides, pyridine and quinoline $\mathrm{N}$-oxides are the most frequently used oxidants.

\subsection{Alkyne Oxidation}

The first case of alkyne oxidation by a pyridine $\mathrm{N}$-oxide was realized intramolecularly without metal catalysis. ${ }^{19}$ Under short-time-thermolysis conditions (contact time ca. $10 \mathrm{~s}$ ), the enynyl pyridine $N$-oxide 2 undergoes a $[6 \pi+2 n]$ electrocyclization to generate cyclic allene intermediate $\mathbf{3}$. Its labile nitrogen-oxygen bond then experiences either heterolytic fission to directly generate the $\alpha$-oxo carbene 4 or homolysis and subsequent orbital rearrangement to arrive at the same intermediate. Two competing pathways ensues: the nascent pyridine ring cyclizes to the carbene center to form the indolizine product $\mathbf{5}$, or a Wolff rearrangement followed by a cyclization results in the formation of the quinolizinone $\mathbf{6}$ (Scheme 6).
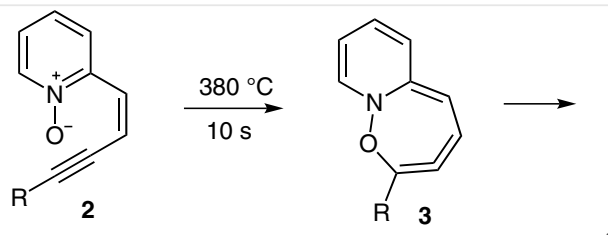

$\mathrm{R}^{1}=\mathrm{H},{ }^{\mathrm{t}} \mathrm{Bu}, \mathrm{Ph}$<smiles>[R]C(=O)/C=C\c1ccccn1</smiles>
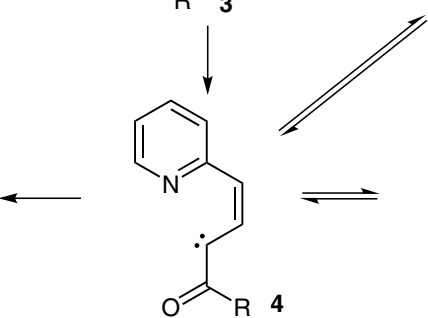<smiles>CCCC=CC=C1C=CC=CN1</smiles>

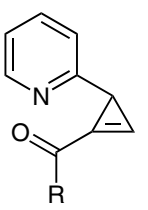<smiles>O=c1c(P)ccc2ccccn12</smiles><smiles>[R]C(=O)c1ccc2ccccn12</smiles>

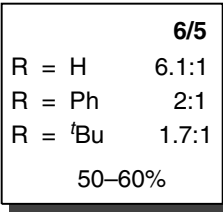<smiles>C1CC2CCCC2C1</smiles>

Scheme 6

The advent of homogeneous gold catalysis ${ }^{20}$ recently led to the development of various alkyne oxidations by heteroarene $N$-oxides. Owing to the potent $\pi$ acidities of cat- 
ionic gold(I) complexes, they can readily coordinate to alkynes and effectively activate the carbon-carbon triple bond toward attack by nucleophiles. Among a range of nucleophiles examined, pyridine $\mathrm{N}$-oxides and specifically 2bromopyridine $\mathrm{N}$-oxide and 3,5-dichloropyridine $\mathrm{N}$-oxide, were first employed by Zhang and co-workers in $2010^{21}$ as suitable oxidants for gold-catalyzed oxidations of homopropargylic alcohols, which resulted in the formation of dihydrofuranones in fair to good yields (Scheme 7). Mechanistically, ${ }^{22}$ the ynophilic cationic gold(I) complex, $\mathrm{Ph}_{3} \mathrm{PAu}^{+}$, first coordinates to the carbon-carbon triple bond ${ }^{23}$ of the substrate and hence activates it toward nucleophilic attack by the pyridine $N$-oxide. The thus-generated alkenylgold intermediate $\mathbf{H}$ then undergoes heterolytic fragmentation of the weak nitrogen-oxygen bond, thereby revealing an $\alpha-$ oxo gold carbene intermediate, namely I. This highly electrophilic metal carbene is trapped by the tethered hydroxy group to afford the isolated product. Notably, pyridine $\mathrm{N}$ oxides were uniquely effective in this reaction while other nucleophilic oxidants such as various sulfoxides ${ }^{24}$ and tertiary amine $\mathrm{N}$-oxides led to poor or no reaction. Methanesulfonic acid (1.2 equiv) was necessary in this reaction in order to prevent catalyst coordination and hence deactiva-
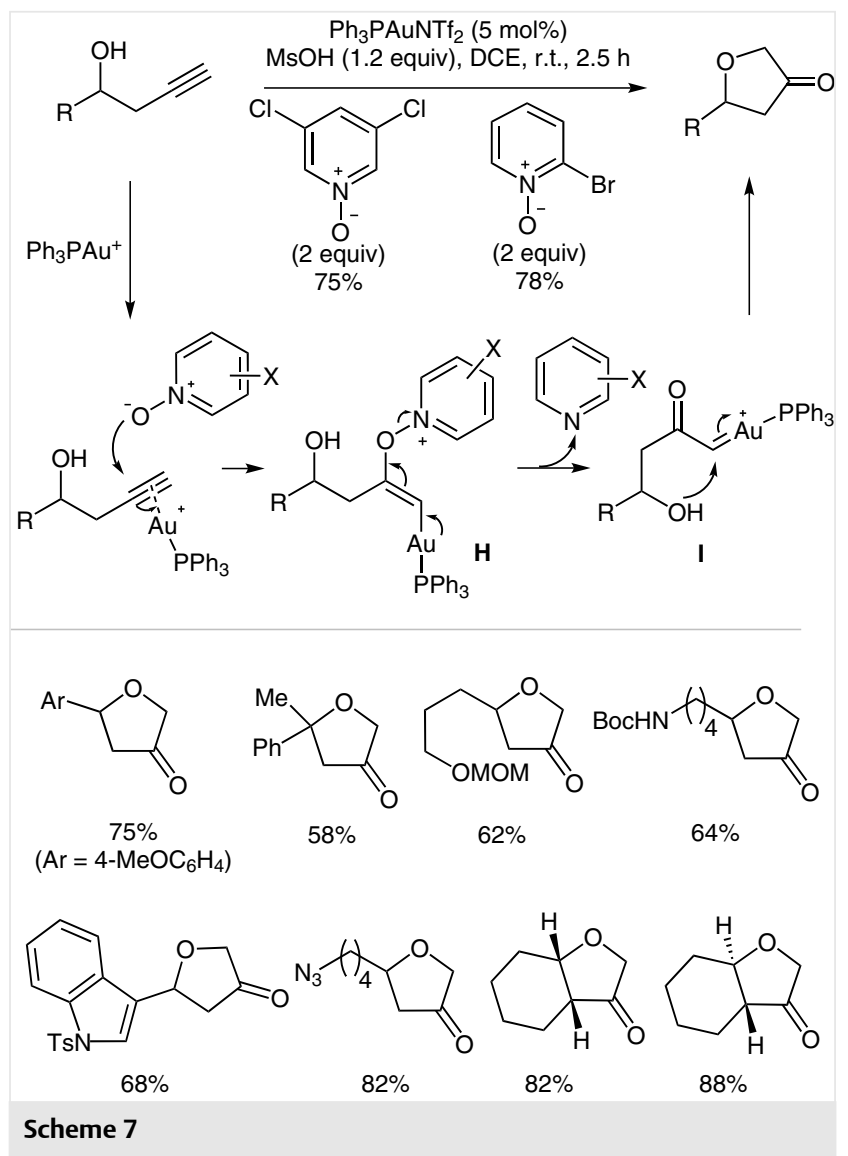

tion by the pyridine byproduct. However, acid-sensitive MOMO and NHBoc groups were tolerated due to the buffering by the slightly basic $N$-oxide.

Of importance is that the net result of such a gold-catalyzed oxidation of a carbon-carbon triple bond, as exemplified by the above study, is the generation of an $\alpha$-oxo gold carbene moiety as in I. As $\alpha$-oxo metal carbenes/carbenoids are typically accessed via metal-promoted dediazotization of $\alpha$-diazo ketones, ${ }^{25}$ this oxidative approach permits the replacement of hazardous, potentially explosive and mostly not commercially available diazo compounds with benign and readily available alkynes in the realm of gold catalysis (Scheme 8).

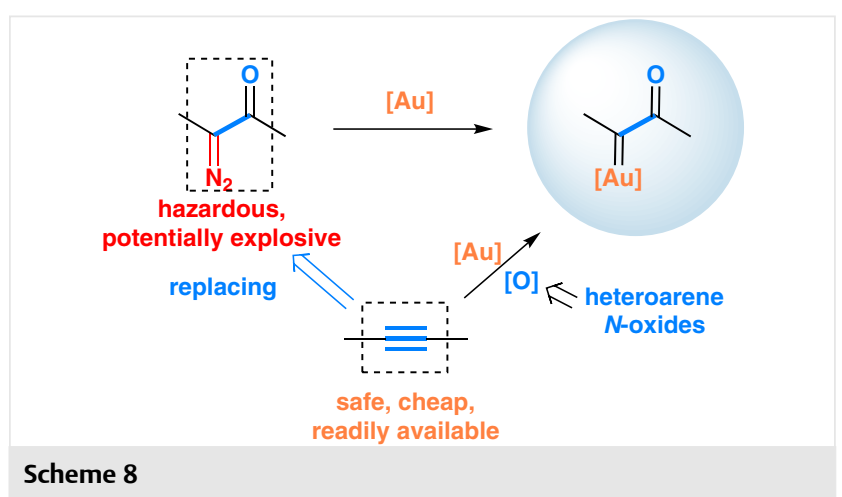

This facile and safe access to synthetically versatile $\alpha$ oxo gold carbenes has attracted broad interest, and many additional synthetic methods have been developed. ${ }^{26}$ Among them, a later work ${ }^{26 b}$ by the same research group revealed that 8 -alkylquinoline $N$-oxides (alkyl $=\mathrm{Me}$, Et, or $i$ $\mathrm{Pr}$ ) are better oxidants than substituted pyridine $N$-oxides in the oxidation of internal alkynes (Scheme 9). This observation is generally true with other substrate types, and can be attributed to a combination of the decent nucleophilicities of these quinoline $\mathrm{N}$-oxides and their labile nitrogenoxygen bond. In addition, as the reduced quinoline possesses a ring nitrogen shielded by the 8-alkyl group, it is no longer able to coordinate to catalytically active cationic gold(I) to a significant extent; as a result, no acid additive is needed, and the oxidative gold catalysis under these non-acidic conditions can tolerate a broad range of functional groups.

As shown in the scheme, the oxidation with 8-isopropylquinoline $N$-oxide could be performed at a temperature as low as $-20^{\circ} \mathrm{C}$, indicating facile formation of the gold carbene intermediate; moreover, the oxidant attacks highly regioselectively at the less hindered end of a sterically biased carbon-carbon triple bond, thereby leading to selective formation of the enone products such as 7. In addition, electronic factors such as conjugation ${ }^{27}$ and inductive effects can also impose good to excellent regioselectivity under the reaction conditions, as demonstrated in the cases of $\mathbf{8}$ and 9. This regioselective oxidation of alkynes into enones offers a synthetically useful strategy of masking enones as 


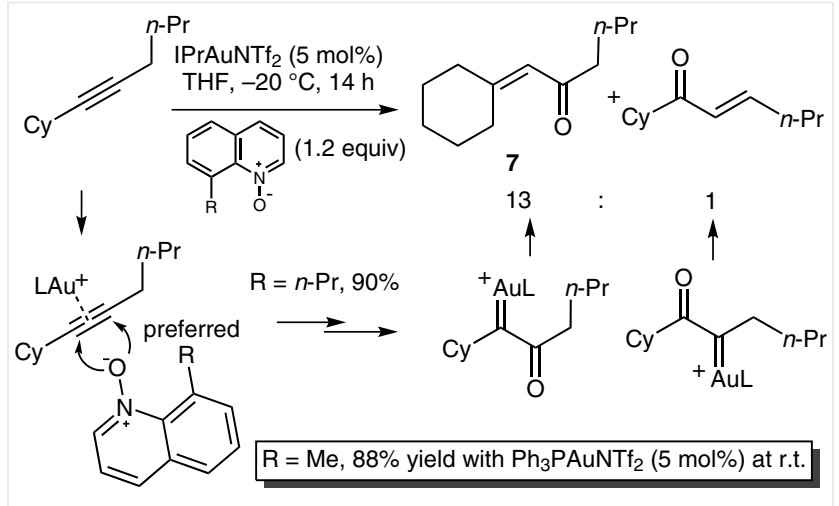<smiles>Cc1ccc(C)cc1</smiles>

$71 \%(11: 1)$

$\left(-20^{\circ} \mathrm{C} ; 48 \mathrm{~h}\right)$<smiles>CCCC=CC(=O)C1=CCCCC1</smiles>

8 $85 \%(>50: 1)$ (r.t., $1 \mathrm{~h})$

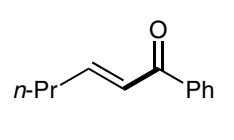

9

$84 \%(11: 1)$

(r.t., 26 h)
Scheme 9

alkynes, which may prove to be of unique synthetic utility when functional group compatibility is an issue due to the diverse reactivities of the enone functionality. Indeed, this chemistry has been applied as a key step in the total syntheses of both citrinadins $A^{28}$ and $B$ (Scheme 10). ${ }^{29}$ Of note is the range of functional groups tolerated in these transformations.

Another notable development of this topic was reported in $2012,{ }^{30}$ where the highly electrophilic $\alpha$-oxo gold carbene moiety, capable of halide abstraction from dichloroethane solvent, ${ }^{31}$ was tempered toward efficient intermolecular trapping by stoichiometric nucleophiles such as carboxamides (Scheme 11). The key feature was the use of Mor-DalPhos, ${ }^{32}$ a $P, N$-bidentate ligand, which enabled the formation of a tris-coordinated gold center in the carbene intermediate $\mathbf{J}$; owing to the additional electron donation by the nitrogen atom to the gold center, a better back-donation by the metal to the electrophilic carbene center is expected, which should lower its reactivity and in turn facilitate its selective trapping. This rationale was supported by
DFT calculations. 8-Methylquinoline $\mathrm{N}$-oxide was again the preferred oxidant, and without any acid additive, the reaction offered the facile preparation of various 2,4-disubstituted oxazoles.

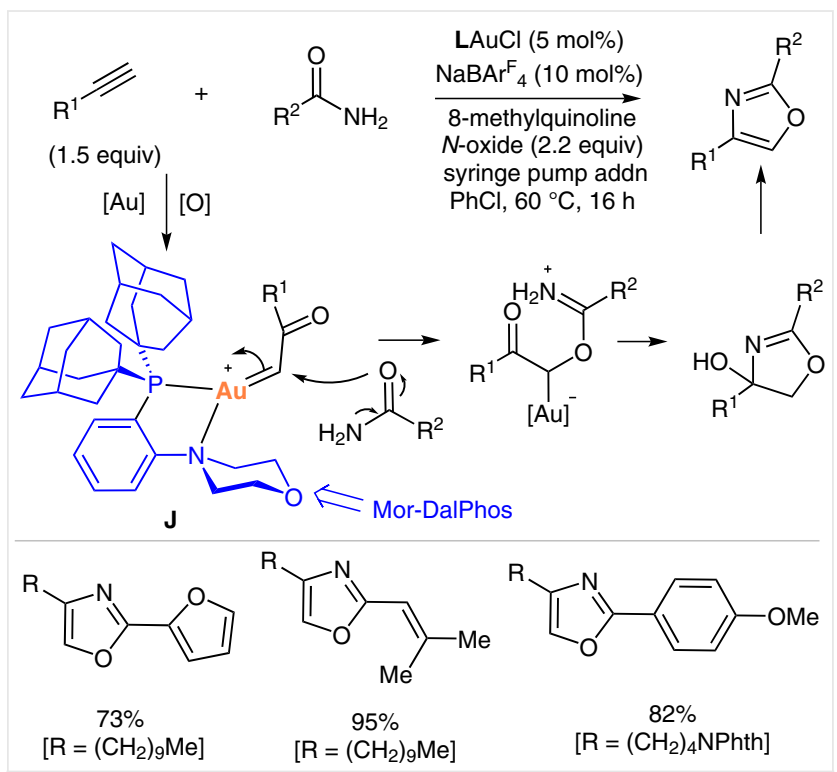

Scheme 11

In some cases, ${ }^{33,34}$ however, gold-catalyzed oxidation of alkynes by pyridine or quinoline $\mathrm{N}$-oxides might diverge to more facile pathways from vinyloxypyridinium intermediates of type $\mathbf{H}$ (see Scheme 7) and hence not engage the intermediacy of an $\alpha$-oxo gold carbene. For example, Liu and co-workers reported that a gold-catalyzed oxidative cyclization using 8-methylquinoline $\mathrm{N}$-oxide as the oxidant offered a highly efficient access to cyclopentenone derivatives (Scheme 12). ${ }^{33}$ While the net outcomes appear to be intramolecular $\mathrm{C}-\mathrm{H}$ insertions by $\alpha$-oxo gold carbenes, detailed mechanistic studies suggested that a 1,5-hydride migration by the initially formed vinyloxyquinolinium $\mathbf{K}$ might be preferred over, and hence bypass, the carbene formation, as the corresponding diazo substrates exhibited a contrasting trend of reactivity.

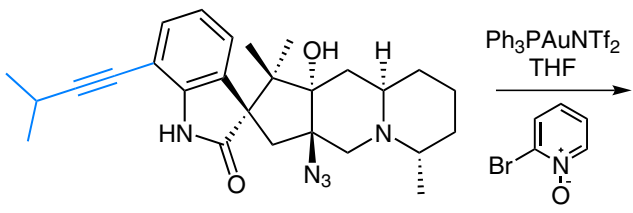

Scheme 10 
<smiles>[2H]Cc1ccccc1C#C</smiles>

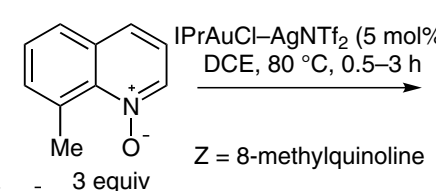<smiles>[R]C1CC(=O)c2ccccc21</smiles>

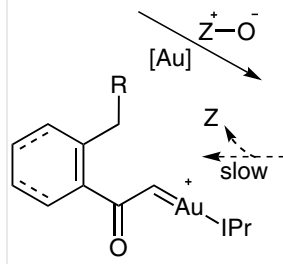<smiles>[Z]O/C(=C/[AlH]C([R])C)c1ccccc1C([R])[3H]</smiles>

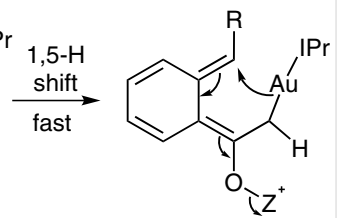<smiles>[R]C1CC(=O)c2ccccc21</smiles><smiles>O=C1CC(c2ccccc2)C2=C1c1ccccc1CC2</smiles>

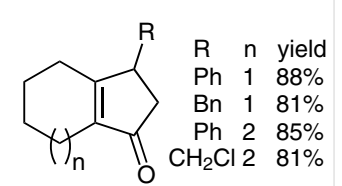

Scheme 12

The heteroaromatic byproduct generated during the oxidative gold catalysis is not necessarily a bystander and can trap the nascent highly electrophilic gold carbene intermediate. ${ }^{21}$ For example, during the study of intramolecular cyclopropanation reaction by Liu, ${ }^{26 d}$ the polycyclic tetrahydropyrroloquinoline $\mathbf{1 0}$ was formed in 34\% yield (Scheme 13). ${ }^{35}$ The yield of $\mathbf{1 0}$ could be improved by the addition of 1.5 equivalents of extra 8-methylquinoline. The reaction likely proceeds via the quinolinium gold intermediate $\mathbf{L}$, which upon releasing the gold catalyst delivers the azomethine ylide $\mathbf{M}$. The ensuing diastereoselective intramolecular 1,3-dipolar cycloaddition affords the observed product. An intramolecular oxidation of carbon-carbon triple bond by a tethered pyridine $N$-oxide also engages the heteroarene in subsequent transformations. ${ }^{36}$

In addition to the gold-catalyzed oxidation of alkynes with pyridine or quinoline $\mathrm{N}$-oxides, related oxidations using rhodium catalysts have been developed. ${ }^{37}$ As shown in Scheme 14, with electronically activated ynamide substrates, the active rhodium catalyst generated from $\left[\mathrm{Rh}(\mathrm{CO})_{2} \mathrm{Cl}\right]_{2}$ and $\mathrm{P}\left[\mathrm{OCH}\left(\mathrm{CF}_{3}\right)_{2}\right]_{3}$ behaves as a $\pi$ Lewis acid, similar to cationic gold(I), and promotes nucleophilic attack by 3,5-dichloropyridine $\mathrm{N}$-oxide. The adduct is then transformed into an $\alpha$-oxo rhodium carbene intermediate (i.e., $\mathbf{N}$ ), which should possess different reactivity from its gold counterpart. In this case, the rhodium carbene moiety in $\mathbf{N}$ can cyclopropanate a tethered alkene or, as shown, undergo metathesis with a similarly tethered alkyne. The new rhodium carbene generated (i.e., $\mathbf{0}$ ) would be oxidized by the same $\mathrm{N}$-oxide to deliver the 4-acyl-2-oxopyrroline product. Notably, the related rhodium-catalyzed oxidation of normal or electron-deficient alkynes is not known, indicating that cationic gold(I) catalysts are in general better $\pi$ Lewis acids than rhodium(II) catalysts.
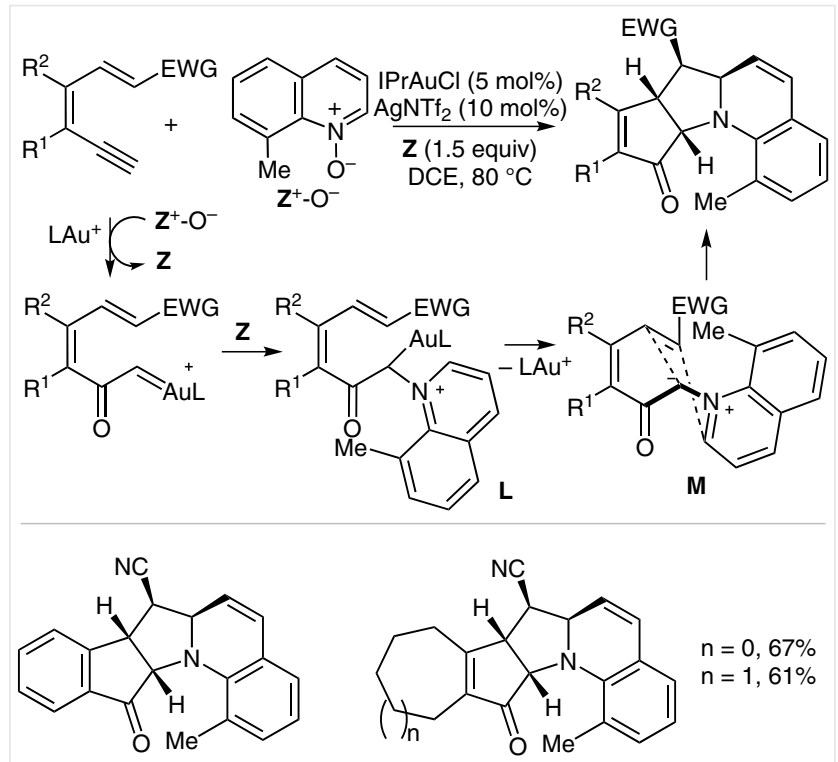

$10,78 \%$

(34\% without extra Z)

Scheme 13

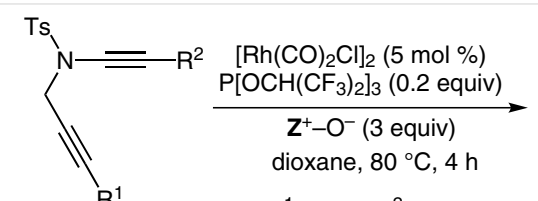

$\mathbf{Z}=3,5-\mathrm{Cl}_{2} \mathrm{Py}$

$\mathrm{R}^{1} \quad \mathrm{R}^{2} \quad$ yield

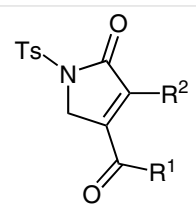

$\mathrm{Z}=3,5-\mathrm{Cl}_{2} \mathrm{Py}$

$\begin{array}{crr}\mathrm{Ph} & \mathrm{Ph} & 67 \% \\ 4-\mathrm{MeOC}_{6} \mathrm{H}_{4} \mathrm{Ph} & 76 \% \\ \mathrm{Me} & \mathrm{Ph} & 56 \%\end{array}$

[Rh] $\begin{array}{cccc}\mathbf{z}^{+} & \mathrm{Me} & \mathrm{Ph} & 56 \% \\ \mathrm{O}^{-} & 4-\mathrm{MeOC}_{6} \mathrm{H}_{4} \mathrm{H} & 80 \%\end{array}$

$\mathrm{z}_{1}^{+\uparrow}$

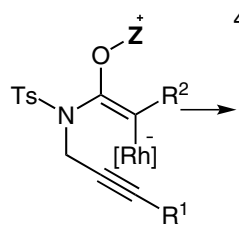

$4-\mathrm{MeOC}_{6} \mathrm{H}_{4} 2-\mathrm{FC}_{6} \mathrm{H}_{4} 75 \%$<smiles>[H]/C=C\C(=O)N(C)CC#N</smiles>

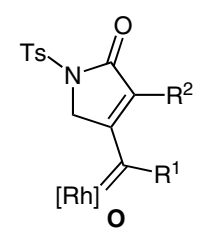

Scheme 14

A palladium-catalyzed double oxidation of diphenylacetylene by pyridine $\mathrm{N}$-oxide was realized under rather harsh conditions (Scheme 15). ${ }^{38}$ It was proposed that a catalytically active palladium(II) species is generated via the oxidation of palladium-on-carbon with the $\mathrm{N}$-oxide and acts as a $\pi$ Lewis acid to promote the addition of the oxidant to the carbon-carbon triple bond. Instead of invoking a probable formation of a palladium carbene, the authors proposed that the adduct $\mathbf{P}$ would be attacked by another molecule of pyridine $\mathrm{N}$-oxide in an $\mathrm{S}_{\mathrm{N}} 2$ '-like manner. Notably, the pyridine $\mathrm{N}$-oxides with either an electron-donating 
4-methoxy or an electron-withdrawing 4-nitro substituent were much less effective, affording the diketone product in $52 \%$ and $34 \%$ yield, respectively.

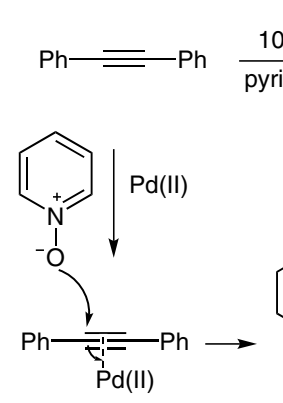

Scheme 15
The copper(I) complex $\mathrm{Cu}(\mathrm{NCMe})_{4} \mathrm{NTf}_{2}$ was shown by Gagosz $^{39}$ to catalyze the oxidative cycloisomerization of alkynyl oxiranes and oxetanes. While the oxirane substrates are transformed into various butenolides, the reactions with alkynyl oxetanes exhibit two competing pathways, the preferences of which are controlled by the pyridine $\mathrm{N}$-oxide used. As shown in Scheme 16, the Lewis acidic copper(I) complex likely activates the substrate via coordination to both the carbon-carbon triple bond and the oxetane ring oxygen. As such, a nucleophilic pyridine $\mathrm{N}$-oxide would attack the alkyne terminus to arrive at the allenoxypyridium intermediate $\mathbf{Q}$ which would undergo either a direct $S_{N} 2^{\prime}$ type cyclization to afford the aldehyde $\mathbf{1 1}$ or a copper(I)promoted 6-endo-trig cyclization followed by elimination to afford the unsaturated lactone 12. What is interesting is that a moderate selectivity (1.9:1) toward $\mathbf{1 1}$ in the case of pyridine $\mathrm{N}$-oxide was dramatically enhanced with a more electron-deficient 3-bromopyridine $N$-oxide, which was ascribed to the improved nucleofugality of 3-bromopyridine; in contrast, the use of a more electron-rich 4-methoxypyridine $\mathrm{N}$-oxide led to a complete reversal of selectivity, and 12 was the only isolated product in $74 \%$ yield. This outcome was attributed to the decreased nucleofugality of 4-methoxypyridine and its enhanced ability to accommodate positive charges.

The isomerization of terminal alkynes to metal vinylidenes is a much employed strategy for method development. ${ }^{40}$ However, there has been only limited success in oxidizing metal vinylidenes into ketenes. ${ }^{41}$ In a recent study by Lee, ${ }^{42}$ pyridine $\mathrm{N}$-oxides were proven to be versatile oxidants for the transformation (Scheme 17). The ketene or rhodium-ketene complex generated underwent either facile nucleophilic trapping to yield carboxylic acid derivatives, or a Staudinger ketene imine cycloaddition ${ }^{43}$ to deliver $\beta$ -

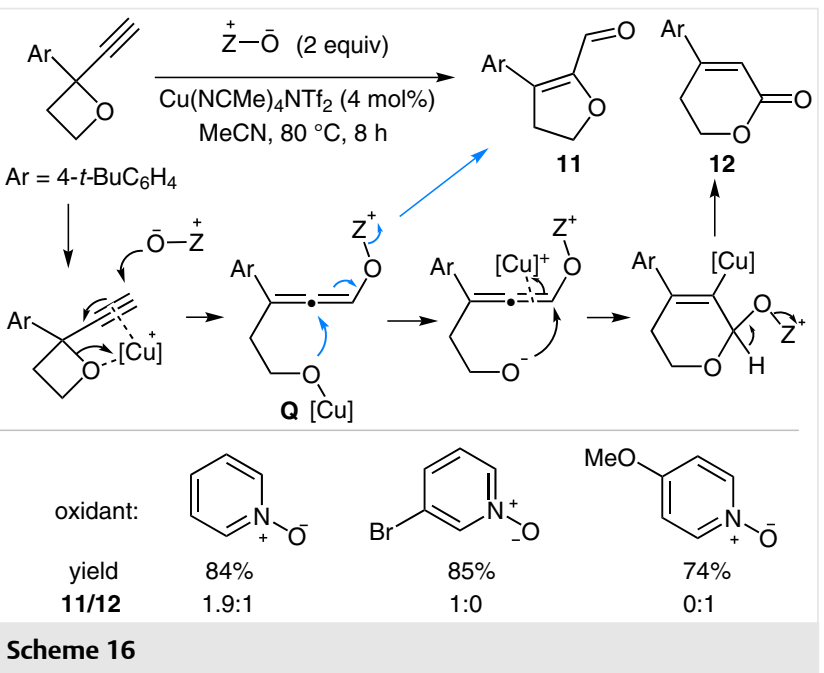

lactams. ${ }^{44}$ Notably, sulfoxides, another class of nucleophilic oxidants, were suitable only for the intramolecular cases. A related ruthenium catalysis was also realized using tethered sulfoxides as oxidants at around the same time. ${ }^{45}$

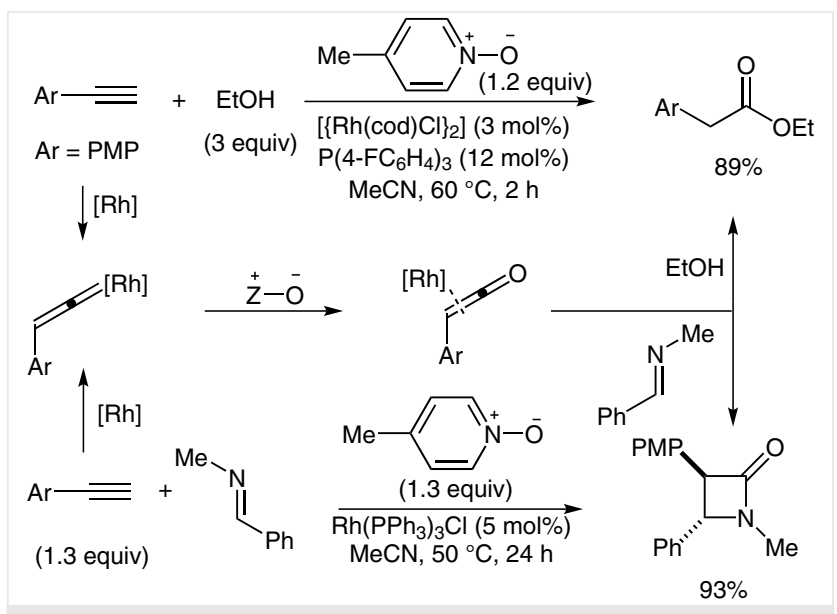

Scheme 17

Despite the widespread use of metal catalysis in the oxidation of alkynes by heteroarene $N$-oxides, there are several metal-free exceptions. For example, with 2-ethynylaniline substrates, a Brønsted acid was used to promote the addition of pyridine $\mathrm{N}$-oxides via the protonated - and hence activated - intermediates R; synthetically useful tetrahydropyrroloquinolinone products were eventually formed in moderate to good yields (Scheme 18). ${ }^{46}$ Notably, the alkynes used in this case can be considered as vinylogous ynamines and are electron-rich, which is necessary as electron-neutral alkynes cannot be readily activated under the employed acidic conditions. 


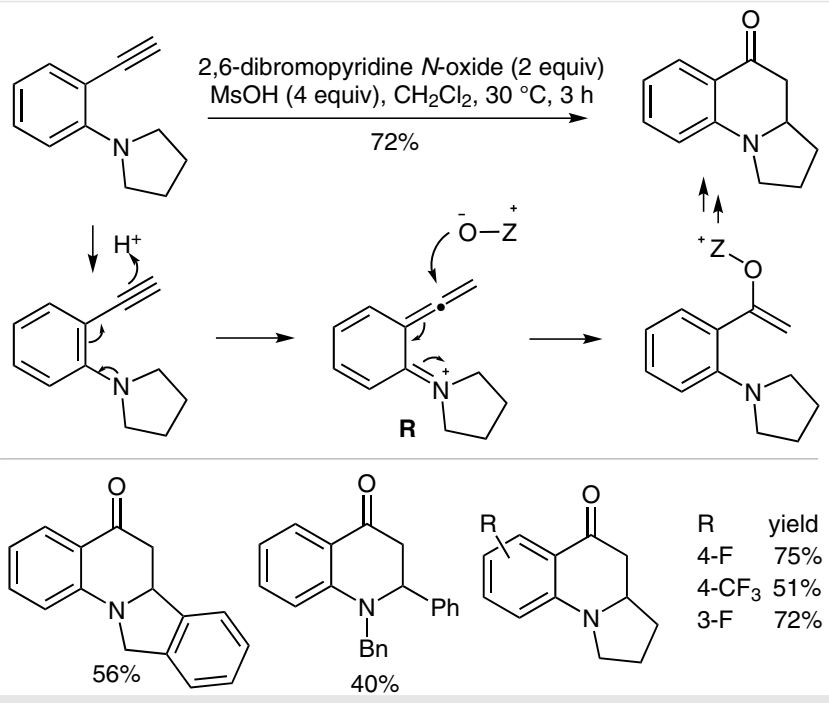

Scheme 18

Another case of metal-free oxidization was also achieved with electron-rich alkynes under acidic conditions. As shown in Scheme 19, the alkynyl aryl ether 13 underwent oxidative cyclization to form the benzofuranone 14 in a good yield (as determined by gas chromatrography). ${ }^{47}$ A likely mechanism entails an initial protonation of the carbon-carbon triple bond and a subsequent $\mathrm{N}$-oxide attack. The conversion of the thus-formed adduct 15 to 14, although not allowed under Baldwin's rules, was also proposed in an earlier related report. ${ }^{34}$

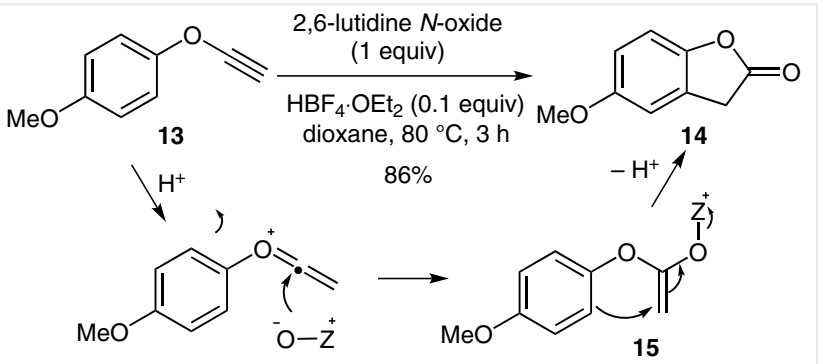<smiles>CC(C)(C)c1ccc2c(c1)CC(=O)O2</smiles>

Scheme 19

\subsection{Allene Oxidation}

The oxidation of allenes by heteroaromatic $\mathrm{N}$-oxides has, surprisingly, attracted little effort, which might be attributable to the difficulty in controlling the regiochemistry of the initial addition. An early study is shown in Scheme $20 .{ }^{48}$ Terminal allenes were converted into $\alpha$-methanesulfonyloxy methyl ketones by using a highly active gold(I) cata- lyst, namely (4-CF $\mathrm{CF}_{3} \mathrm{Ph} \mathrm{PAuNTf}_{2}$, and 3,5-dichloropyridine $\mathrm{N}$-oxide as the oxidant. The proposed mechanism involves an initial gold-catalyzed regioselective addition of the $\mathrm{N}$ oxide to the allene sp-hybridized carbon, a subsequent protodeauration and a final $S_{N} 2$ '-type attack by mesylate.

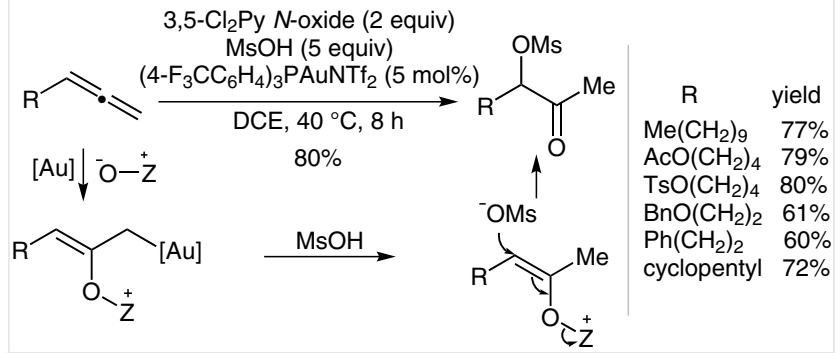

Scheme 20

\subsection{Carbene Oxidation}

Pyridine $N$-oxide was also utilized for the oxidative demetalation of Fischer carbene complexes. ${ }^{49}$ For example, the Fischer carbenes 16, synthesized from [3+2] cycloaddition between an azomethine imine and 1-alkynyl Fischer carbene complexes, were converted into the corresponding bicyclic ester 17 by using pyridine $\mathrm{N}$-oxide (Equation 4 ). ${ }^{49 \mathrm{e}}$<smiles>[M]C(OCC)C1=C(c2ccccc2)N2C(=O)CC(c3ccccc3)N2C1c1ccccc1</smiles>

16

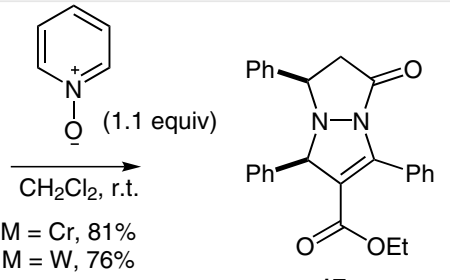

17
Equation 4 


\section{Heteroaromatic $\mathrm{N}$-Oxides as Substrates}

Among the many types of reactions using heteroaromatic $\mathrm{N}$-oxides and their functionalized derivatives as substrates, the regioselective functionalization of carbonhydrogen bonds offers streamlined synthetic routes and is of significant synthetic utility. Lately, much progress has been reported in this area, as discussed in this section.

\subsection{Deoxygenative ortho-C-H Functionalization with Prior Activation}

Complementary to nucleophilic aromatic substitutions of ortho-halogenated $\mathrm{N}$-heteroarenes, non-functionalized heteroaromatic $\mathrm{N}$-oxides have been employed widely to achieve ortho-substitutions, resulting in net $\mathrm{C}-\mathrm{H}$ functionalizations. ${ }^{50}$ With weak nucleophiles such as amines, chlorides and cyanides, direct attack at the ortho position does not occur, owing to its weak electrophilicity. However, as shown in Scheme 21, initial activation of an $\mathrm{N}$-oxide by attaching an electrophilic species to the negatively charged oxygen would enhance the electrophilicity of the ortho position and thereby dramatically accelerate nucleophilic attack, which would in turn yield an ortho-substituted heteroarene (i.e., 18) upon subsequent rearomatization, although 4-substituted side products may be formed as well. Commonly employed activating agents include methyl triflate, $p$-toluenesulfonic anhydride, $p$-toluenesulfonyl chloride, benzoyl chloride, bromotripyrrolidinophosphonium hexafluorophosphate (PyBroP), and triphosgene. In cases where substituents other than the counter-anion of the activating reagent are desired, the reactions are typically performed in two steps and weakly nucleophilic counter-anions are used. For example, methyl triflate ${ }^{50 a}$ and $p$-toluenesulfonic anhydride (Equation 5) 50c,e were used in the synthesis of 2-aminated pyridines under mild conditions. In a mild, one-step reaction using PyBroP as the activating reagent, an amazingly broad scope of nucleophiles including amines, ${ }^{50 \mathrm{~d}}$ azoles, phenols, amides, thiols and stabilized carbonucleophiles $^{50 \mathrm{i}}$ were used to effect deoxygenative ortho-substitution of pyridine $\mathrm{N}$-oxides (Equation 6). Notably, this reaction is devoid of 4-substituted and halogenated side products and, moreover, the one-step protocol suggests that the reactions between nucleophiles and PyBroP, if any, might be reversible.
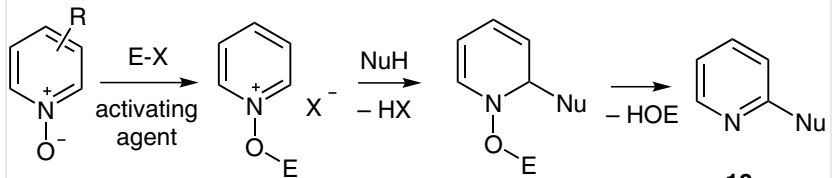

18

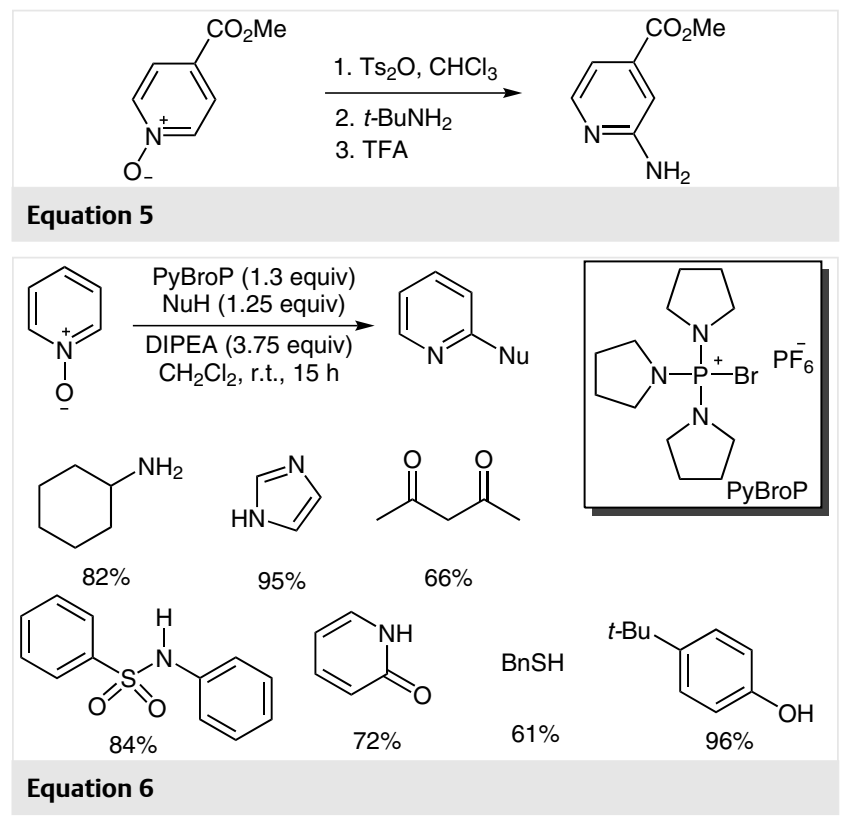

When the counter-anion of the activating reagent is the desired 2-substituent, this deoxygenative substitution can be readily performed in one step. An example is shown in Equation 7. ${ }^{50 a}$ Interestingly, in the case of 1-alkylpyrazole2-oxides, halogenation occurred at C5 instead of C3 (Equation 8). . $^{0}$

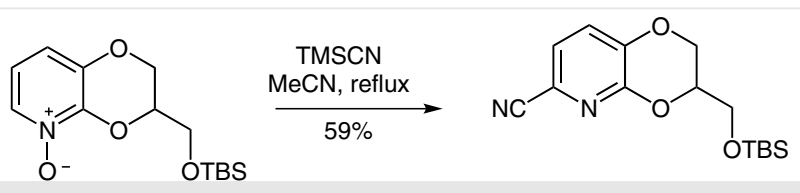

Equation 7

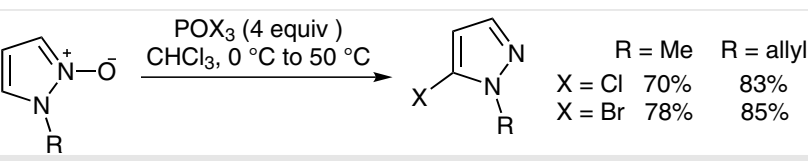

Equation 8

A versatile approach to installing amide groups at the pyridine 2-position involves the reaction of pyridine $\mathrm{N}$-oxides with imide chloride, in the so-called Abramovitch reaction. ${ }^{51}$ In an improved mild protocol (Scheme 22), ${ }^{50 f}$ the reactive chloride, generated in situ from treating a secondary carboxamide with stoichiometric oxalyl chloride in the presence of a moderate base, reacted with a pyridine $\mathrm{N}$-oxide to form the intermediate $\mathbf{1 9}$, which likely underwent electrocyclic closure to form the bicyclic dihydropyridine 20. A base-promoted fragmentation of the oxadiazoline ring of $\mathbf{2 0}$ then regenerated the pyridine ring and installed the amide group at the ring $\mathrm{C} 2$ position. A similar transformation using triflic anhydride and 2-fluoropyridine has been reported. ${ }^{50 j}$ With primary amides, however, similar 
treatments with oxalyl chloride in the absence of base generated acylisocyanates instead of the imido chlorides; they subsequently reacted with quinoline $\mathrm{N}$-oxides to yield quinolines possessing a secondary amide at their C2 position. ${ }^{5 \mathrm{~h}}$<smiles>[R7]N=C([R])Cl</smiles>
one-pot, up to $100 \%$ 20 19<smiles>CC(=O)N(C)c1ccccn1</smiles>

$73 \%$<smiles>CC(=O)N(c1nccc2ccccc12)[N+](=O)[O-]</smiles>

$90 \%$<smiles>CC(=O)N(Cc1ccccc1)c1cccc(C)n1</smiles>

Scheme 22

\subsection{Deoxygenative ortho-C-H Functionalization with Nonstabilized Carbanions}

The reaction of heteroaromatic $\mathrm{N}$-oxides with strongly nucleophilic Grignard reagents typically do not require much substrate activation. An early study ${ }^{52}$ reported the low-yielding formation of the ring-opened product dienal oximes 22, instead of the originally proposed dihydropyridine, upon protonation of $\mathbf{2 1}$ (Scheme 23). Olsson, Almqvist and Andersson discovered in 2011 that the ring opening of $\mathbf{2 1}$ to 22 did not occur as long as the temperature was below $-20^{\circ} \mathrm{C}$. As a result, they developed preparations of 2-substituted pyridines and stereoselective syntheses of substituted piperidines and piperazines under exceptionally mild conditions. ${ }^{53}$ For example, in a one-pot process, 2-substituted pyridines were prepared in fair yields upon treatment of the initial adduct of type $\mathbf{2 1}$ with a dehydrating reagent such as trifluoroacetic anhydride (Scheme 24).$^{54}$ Of note is that the reaction was not contaminated with 4-substituted side products and functional groups such as carboxylate and chloride were tolerated. In addition to the dehydration, the initial adduct could be oxidized back to the pyridine $\mathrm{N}$ oxide, ${ }^{54,55}$ or formed asymmetrically en route to chiral piperidines following reduction (Scheme 24). ${ }^{56}$

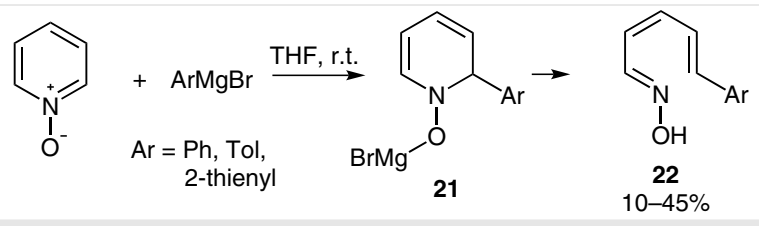

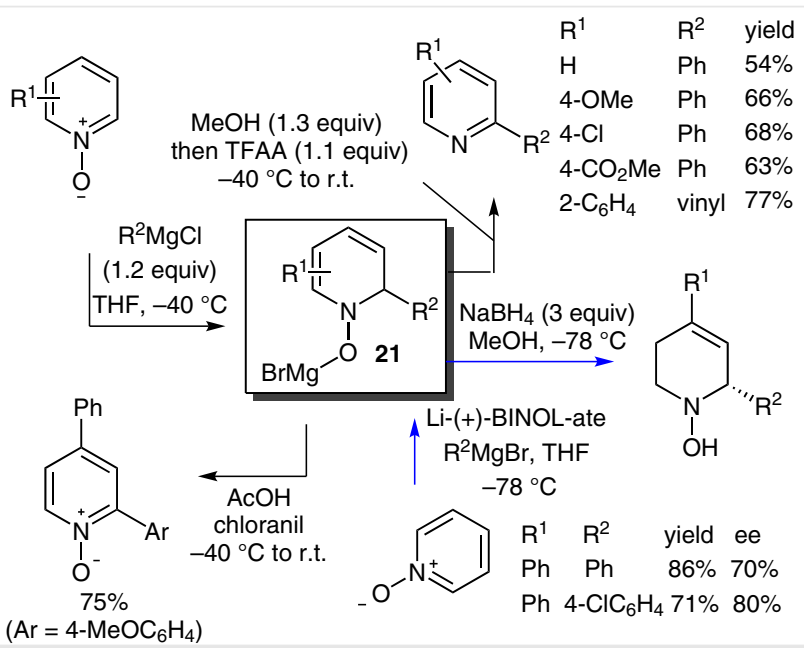

Scheme 24

An improved, one-step deoxygenative ortho-substitution of $\mathrm{N}$-oxides was catalyzed by copper(I) chloride (Equation 9). ${ }^{57}$ The addition of Lewis acidic magnesium chloride or lithium fluoride improved the yield dramatically. The reaction featured mild reaction conditions, no need for a dehydrating reagent, and a broad reaction scope as alkyl, aryl and alkenyl Grignard reagents were all suitable, and functional substituents on the heteroarene ring such as bromine and free hydroxy groups were tolerated. Notably, the twostep method in Scheme 24 did not work well with alkyl Grignard reagents.

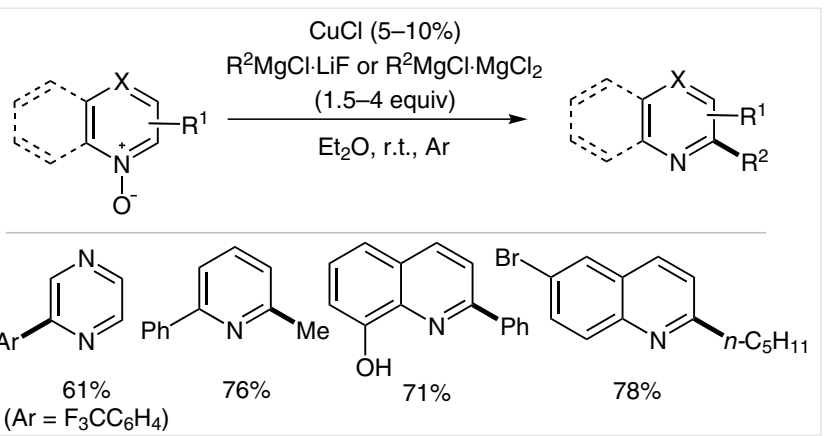

Equation 9

Metal-free reactions between quinoline $\mathrm{N}$-oxide and silylated arylacetylenes or 2-trimethylsilylbenzothiazole were realized with the use of organic superbase P4-t-Bu $\left(\mathrm{p} K_{\mathrm{BH}+}\right.$ in acetonitrile $\left.=42.7\right)$ as catalyst, and 2-substituted quinolines were obtained in good yields (Equation 10)..$^{58}$

Scheme 23 
<smiles>[O-][n+]1cccc2ccccc21</smiles><smiles>CN=PN=PN=[N+](C)C</smiles><smiles>Nc1ccc2ccccc2n1</smiles>

$\mathrm{NuH}=$

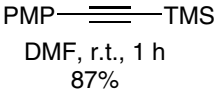<smiles>Cc1nc2ccccc2s1</smiles>

cyclopentyl methyl ether r.t., $17 \mathrm{~h}, 77 \%$

Equation 10

\subsection{Nondeoxygenative C-H Functionalization}

In contrast to the deoxygenative approach discussed above, transition-metal-catalyzed $\mathrm{C}-\mathrm{H}$ activation of $\mathrm{N}$-oxides of pyridine or other heteroarenes offers a direct and versatile strategy for the functionalization of $\mathrm{N}$-heteroarenes not only at the ortho position but also at positions further away. Moreover, readily available halides, including alkyl halides, instead of Grignard reagents are employed as reaction partners, thereby promising better functional group tolerance. Notably, the $\mathrm{N}$-oxide moiety stays intact during the transformation and hence is available for promoting or directing further functionalization of the heteroarene ring, even though an addition reduction step is required to access heteroarene products.

\subsection{1 ortho-C-H Functionalization}

The Fagnou research group pioneered a palladium-catalyzed ortho-selective $\mathrm{C}-\mathrm{H}$ functionalization of a range of azine and azole $\mathrm{N}$-oxides using aryl bromides as the crosscoupling partners. ${ }^{5,59}$ Scheme 25 shows some examples that exhibited high regioselectivities. Mechanistic studies ${ }^{59 f}$ pointed to an inner-sphere concerted metallation-deprotonation pathway instead of an $\mathrm{S}_{\mathrm{E}} \mathrm{Ar}$ and a critical role played by a carboxylate base in the carbon-hydrogen bond cleavage. Notably, the negatively charged $\mathrm{N}$-bound oxygen was not involved in directing the $\mathrm{C}-\mathrm{H}$ activation. The observed regioselectivity may be attributed to the more electropositive nature of the ortho position.

A notable advance in this approach was the use of secondary alkyl halides to replace aryl halides (Equation 11), ${ }^{60}$ which provided a practical method to synthesize alkylated pyridine $\mathrm{N}$-oxides. The involvement of radical species during the carbon-bromine bond cleavage was supported by the observed stereochemistry scrambling and radical rearrangement.<smiles>CC1=CC=CC[C+]=[N+]1[O-]</smiles>

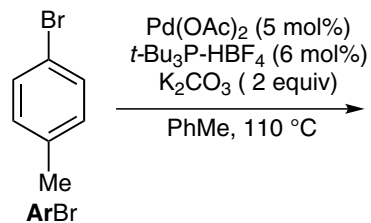<smiles></smiles><smiles></smiles>

$\mathrm{Pd}(\mathrm{OAc})_{2}(5 \mathrm{~mol} \%)$ PhDave-Phos (10 mol\%) $\mathrm{K}_{2} \mathrm{CO}_{3}$ (15 equiv) $\mathrm{PhMe}(0.2 \mathrm{M}), 25^{\circ} \mathrm{C}$

(1.1 equiv) (1 equiv)

$88 \%$<smiles>Cc1c[n+]([O-])c(P)s1</smiles><smiles>COc1cc(Br)cc(OC)c1</smiles>

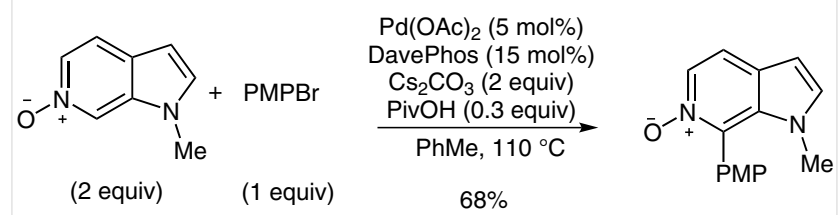

\section{Scheme 25}

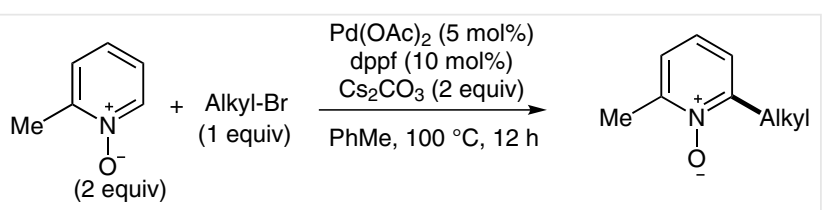<smiles>COc1ccc2c(ccc(C3CCCCC3)[n+]2[O-])c1</smiles>

Equation 11

In addition to palladium catalysis, a copper-catalyzed $\mathrm{C}-\mathrm{H}$ activation and sulfonylation of quinoline $\mathrm{N}$-oxides using arenesulfonyl chlorides was also realized (Equation 12). ${ }^{61}$<smiles>ON=Cc1ccccc1NO</smiles><smiles>[TeH4-]</smiles>

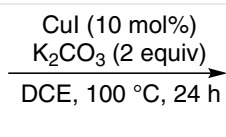<smiles>[O-][n+]1c(S)ccc2ccccc21</smiles>

(1 equiv) (4 equiv)

Equation 12 
Instead of $\mathrm{C}-\mathrm{X}$ bonds, the use of $\mathrm{C}-\mathrm{H}$ bonds as coupling partners to functionalize the ortho $\mathrm{C}-\mathrm{H}$ bonds of the $\mathrm{N}$-oxides offers, in principle, even better step-economy and synthetic efficiency. This oxidative dehydrogenation approach has been successfully applied to ethers, alkenes, arenes and even heteroarene $\mathrm{N}$-oxides. Some representative examples are shown in Scheme 26. For example, simple pyridine $\mathrm{N}$ oxide was arylated selectively at the $\mathrm{C} 2$ position with 40 equivalents of benzene using silver carbonate as the stoichiometric oxidant and palladium(II) acetate as the catalyst, ${ }^{62}$ 1,2,3-triazole $\mathrm{N}$-oxides were regioselectively alkenylated using methyl acrylate in an oxidative Heck reaction or coupled with another $\mathrm{N}$-oxide (e.g., pyridine $\mathrm{N}$-oxide), ${ }^{63}$ and pyridine or quinoline $\mathrm{N}$-oxides were alkylated regioselectively by cyclic ethers. ${ }^{64}$ In the last case, the stoichiometric oxidant, tert-butyl hydroperoxide, was involved in the generation of $\alpha$-ethereal radicals via hydrogen abstraction.

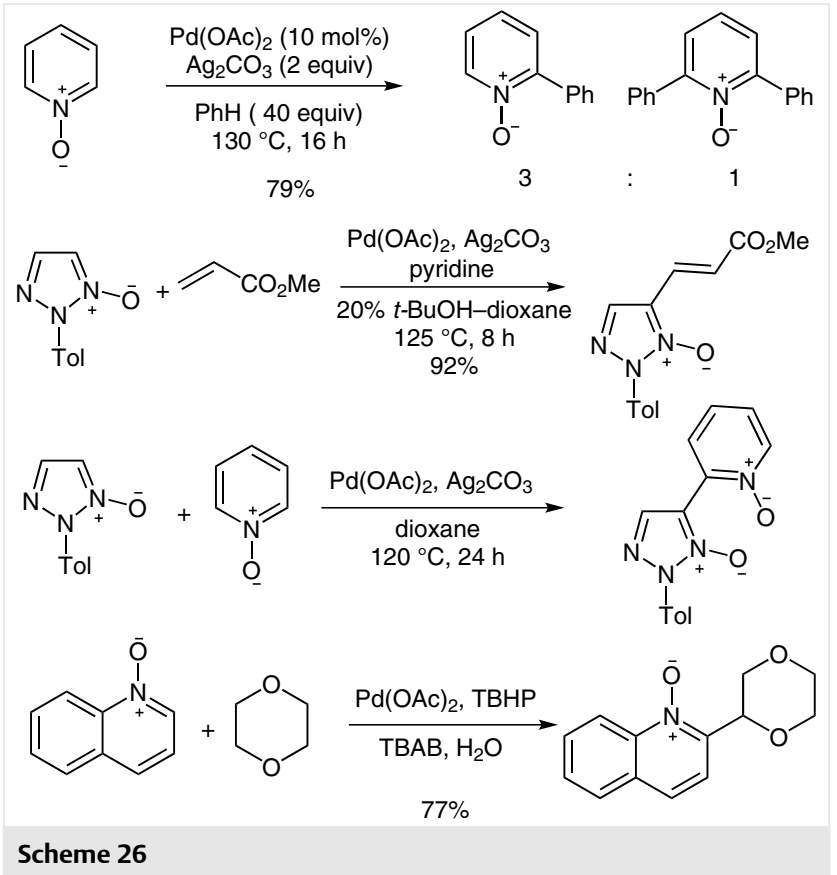

A copper-catalyzed regioselective direct cross coupling between quinoline $\mathrm{N}$-oxides and lactams or secondary amines was realized through the use of silver carbonate as oxidant (Equation 13). ${ }^{65}$ This reaction offered a simple yet direct construction of 2-amino/amidoquinolines and was found to tolerate various nitrogen coupling partners. A later study revealed that the amination reaction could be performed under much milder conditions $\left(50^{\circ} \mathrm{C}\right.$ instead of 120 ${ }^{\circ} \mathrm{C}$ ) and, moreover, by using air as the stoichiometric oxidant (Equation 14). ${ }^{66}$ The key difference was the use of copper(I) iodide as the catalyst.

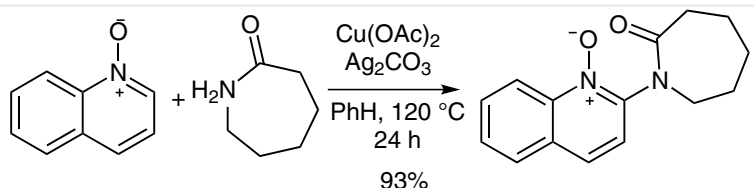

Equation 13
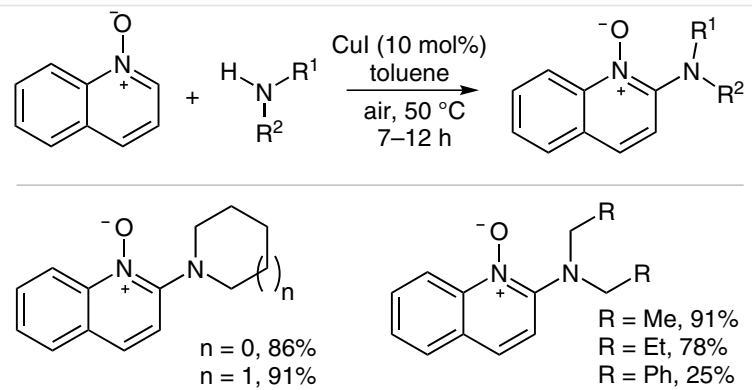

Equation 14

There are other notable ortho-C-H functionalization reactions of heteroarene $\mathrm{N}$-oxides. For example, nickel-catalyzed additions of pyridine $\mathrm{N}$-oxides across internal alkynes have been developed based on regioselective activation of the heteroarene $\mathrm{C} 2-\mathrm{H}$ bond (Equation 15) ${ }^{67}$ The reported reaction conditions were mild, but the scope of the alkyne, due to poor control of regioselectivity, was rather limited. Another case is a direct C2-carboxylation of quinoline $\mathrm{N}$-oxide, which entailed a copper(I)-catalyzed and tert-butyl hydrogen peroxide mediated cross dehydrogenative coupling between aldehydes and quinoline $N$-oxides (Equation 16). ${ }^{68}$

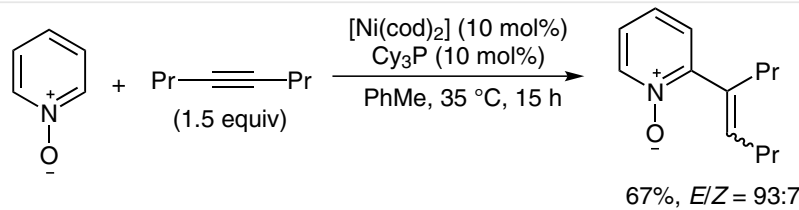

Equation 15

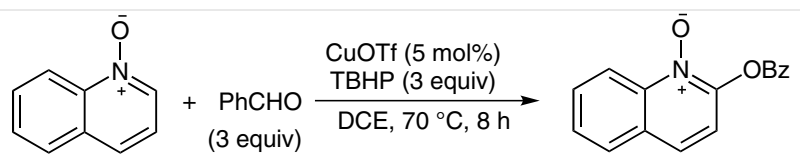

$84 \%$

Equation 16

\subsubsection{N-Oxide Directed ortho-Alkyl C-H Functionaliza- tion}

By using a much stronger base (i.e., sodium tert-butoxide instead of potassium or cesium carbonate ${ }^{5,59}$ ) and a different phosphine ligand, Fagnou and co-workers realized a selective palladium-catalyzed activation of the ortho-alkyl $\mathrm{C}-\mathrm{H}$ bond over the ortho- $\mathrm{C}\left(\mathrm{sp}^{2}\right)-\mathrm{H}$ bond of 2-alkylpyridine $\mathrm{N}$-oxide, which eventually led to arylation at the 2-alkyl 
group instead of at the pyridine ring C6 position (Scheme $27) .{ }^{59 a, e}$ The palladacycle intermediate $\mathbf{S}$, formed upon the deprotonation of the 2-alkyl group of the pyridine $\mathrm{N}$-oxide by strongly basic sodium tert-butoxide, was proposed as the key intermediate that furnished the desired product with the observed chemoselectivity.

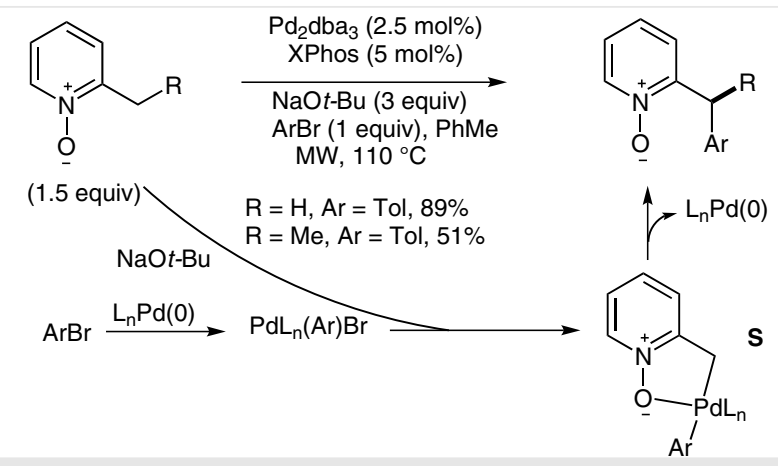

Scheme 27

\subsection{3 $\mathrm{N}$-Oxide Directed Remote C-H Functionalization}

Aside from $\mathrm{C}-\mathrm{H}$ functionalization at the $\mathrm{C} 2$ position of quinoline $\mathrm{N}$-oxides, directed activation of the relatively remote $\mathrm{C} 8-\mathrm{H}$ bond and its subsequent functionalization was recently realized via rhodium catalysis by Matsuo and Shibata. ${ }^{69}$ In the presence of a cationic rhodium(I) catalyst, the addition of the $\mathrm{C} 8-\mathrm{H}$ bond across an alkyne was achieved in fair to good yields (Scheme 28). ${ }^{69}$ The reaction resembles that shown in Equation 15, but occurs at a different carbon-hydrogen bond, highlighting the key roles of different metal catalysts. Mechanistically, a five-membered metallacycle (i.e., $\mathbf{U}$ ) is formed upon $\mathrm{C}-\mathrm{H}$ activation, which is preferred for subsequent reaction with alkynes likely due to its relative stability over the $\mathrm{C} 2-\mathrm{H}$ activation isomer $\mathbf{T}$. This type of remote $\mathrm{C}-\mathrm{H}$ functionalization was independently developed and later expanded by Chang and coworkers ${ }^{70,71}$ to include a range of other functional groups. As shown in Scheme 29, a rhodium-catalyzed direct iodination delivered synthetically versatile iodide $\mathbf{2 3}$ in a good yield, an iridium-catalyzed amidation was highly efficient when tosyl azide was used as the nitrene source, a rhodium-catalyzed alkynylation using TIPS-EBX (25) afforded 8alkynylquinoline $\mathrm{N}$-oxide $\mathbf{2 6}$ in 93\% yield, and an 8-alkylation was readily achieved with the use of diazomaleate. These direct remote $\mathrm{C}-\mathrm{H}$ functionalizations feature very mild reaction conditions, excellent functional group tolerance and broad reaction scopes.

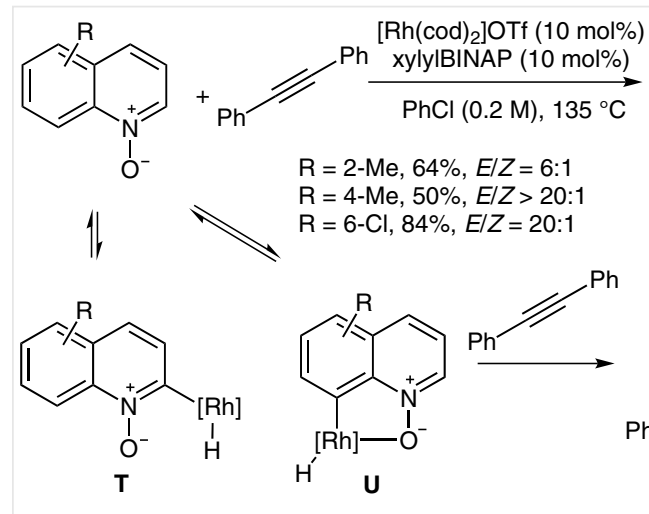

$\left.\right|_{\mathrm{Ph}}$<smiles>[O-]c1ccc[n+]([O-])c1/C(=C/c1ccccc1)c1ccccc1</smiles>

Scheme 28<smiles>[O-][n+]1cccc2cccc(I)c21</smiles><smiles>COC(=O)C(C(=O)OC)c1cccc2ccc[n+]([O-])c12</smiles>

Scheme 29

\subsection{1,3-Dipolar Cycloaddition}

Heteroaromatic $\mathrm{N}$-oxides can react as 1,3-dipoles in [3+2]-cycloaddition reactions with electron-deficient alkenes. Some selected examples reported after 2001 are presented in Scheme 30. ${ }^{72}$ For example, the dipolar cycloaddition between $\mathrm{N}$-methyl maleimide and the quinoline $\mathrm{N}$ oxide $\mathbf{2 7}$ proceeded readily at ambient temperature to afford two diastereomeric cycloadducts in a good combined yield. ${ }^{72 a}$ The $[3+2]$ reaction between pyridine $N$-oxide and phenyl isocyanate led to the formation of primary product 28, which was thermally unstable and transformed at $150{ }^{\circ} \mathrm{C}$ into 2,3 -dihydropyridine derivative 29 by way of a 1,5-sigmatropic rearrangement and eventually decomposed to 2-anilinopyridine in a good yield. ${ }^{72 b}$ Two research groups $^{72 c, d}$ independently studied the [3+2] cycloaddition between in situ generated benzyne and pyridine $\mathrm{N}$-oxide. Interestingly, the cycloadduct $\mathbf{3 0}$, under different conditions, rearranged to either 3-(2-hydroxyphenyl)pyridine (31) or 2-(2-hydroxyphenyl)pyridine (32). The reaction between quinoline $\mathrm{N}$-oxide and electron-deficient hexafluo- 


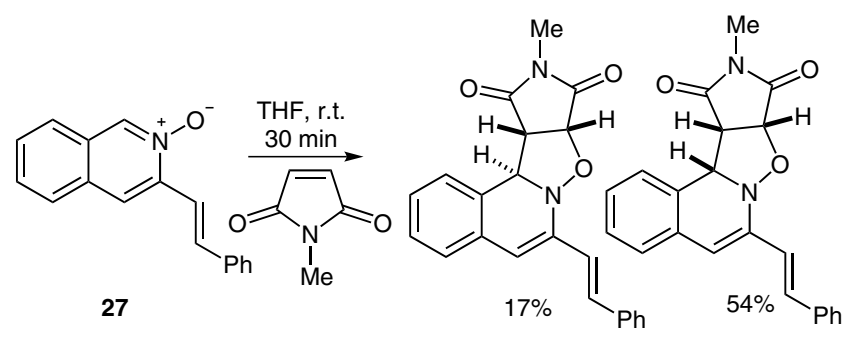

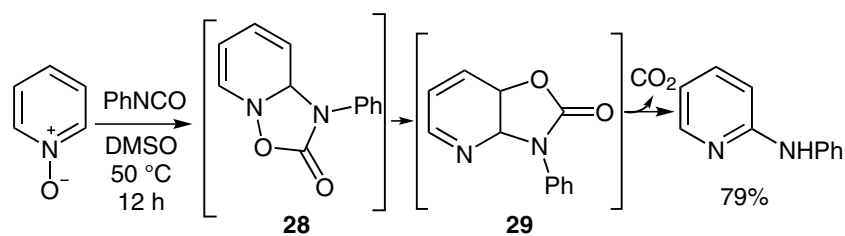

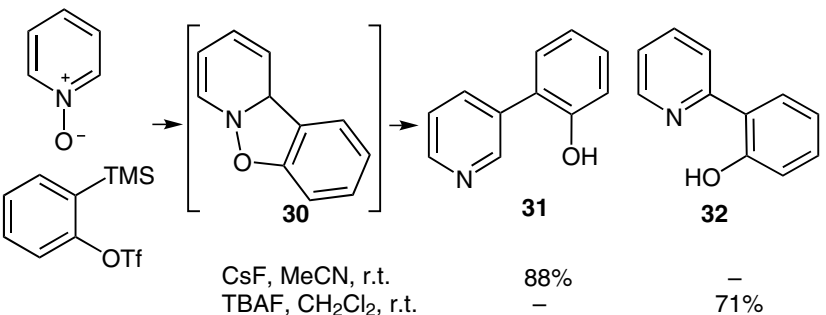

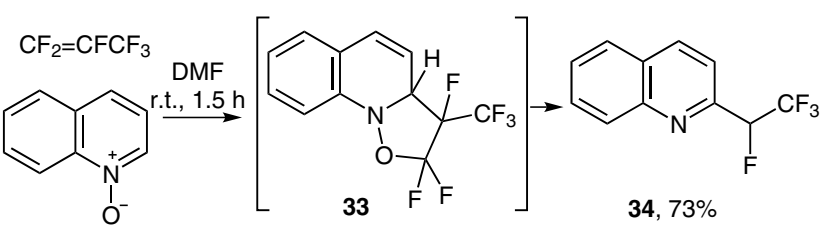

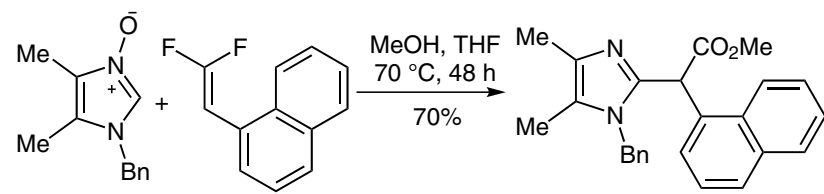

Scheme 30

ropropene proceeded at room temperature to give the cycloadduct intermediate 33, which underwent sequential elimination, rearomatization, and fragmentation to furnish the final fluorinated 2-ethylquinoline 34. ${ }^{72 e, f}$ Other $\mathrm{N}$-oxides such as imidazole $N$-oxide and thiazole $N$-oxide reacted similarly with difluorinated 1-vinylnaphthalene to furnish aryl(heteroaryl)acetates upon subsequent rearomatization and reaction with methanol. ${ }^{72 \mathrm{~g}}$

\section{Conclusion and Outlook}

The chemistry of heteroaromatic $\mathrm{N}$-oxides has experienced rapid growth since 2001 . The combination of a negatively charged and nucleophilic oxygen and a weak nitrogen-oxygen bond enables these $\mathrm{N}$-oxides to be used as versatile nucleophilic oxidants in late-transition-metalcatalyzed oxidation of alkynes and allenes. In the cases of gold catalysis, the oxidation can offer access to highly electrophilic $\alpha$-oxo gold carbene intermediates and thus permit the development of a range of valuable synthetic transformations. The negatively charged oxygen also impacts the heteroarene ring electronically via delocalization and induction and can facilitate regioselective ortho $\mathrm{C}-\mathrm{H}$ functionalizations either in an overall deoxygenative process or by way of transition-metal-catalyzed $\mathrm{C}-\mathrm{H}$ activations. Moreover, it can act as a Lewis basic directing group to enable activation of remote $\mathrm{C}-\mathrm{H}$ bonds, thereby allowing valuable alternative $\mathrm{C}-\mathrm{H}$ functionalizations. Further applications of heteroaromatic $N$-oxides in oxidation reactions catalyzed by transition metals, especially those that are inexpensive and abundant, and in regioselective $\mathrm{C}-\mathrm{H}$ functionalizations of a broader range of heterocycles are expected to continue to enrich the chemistry of heteroaromatic $N$ oxides. 


\section{Acknowledgment}

The authors thank ACS PRF (52040-ND1) and NSF CHE-1301343 for financial support.

\section{References}

(1) Chanzy, H.; Maia, E.; Perez, S. Acta Crystallogr., Sect. B 1982, 38 , 852.

(2) Jaffé, H. H.; Doak, G. O. J. Am. Chem. Soc. 1955, 77, 4441.

(3) Albini, A.; Pietra, S. Heterocyclic N-Oxides; CRC Press: Boca Raton, 1991.

(4) Youssif, S. ARKIVOC 2001, (i), 242.

(5) Campeau, L.-C.; Stuart, D. R.; Leclerc, J.-P.; Bertrand-Laperle, M.; Villemure, E.; Sun, H.-Y.; Lasserre, S.; Guimond, N.; Lecavallier, M.; Fagnou, K. J. Am. Chem. Soc. 2009, 131, 3291.

(6) Brougham, P.; Cooper, M. S.; Cummerson, D. A.; Heaney, H.; Thompson, N. Synthesis 1987, 1015.

(7) Rong, D.; Phillips, V. A.; Rubio, R. S.; Ángeles Castro, M.; Wheelhouse, R. T. Tetrahedron Lett. 2008, 49, 6933.

(8) Murray, R. W.; Jeyaraman, R. J. Org. Chem. 1985, 50, 2847.

(9) Copéret, C.; Adolfsson, H.; Khuong, T.-A. V.; Yudin, A. K.; Sharpless, K. B. J. Org. Chem. 1998, 63, 1740.

(10) Carmeli, M.; Rozen, S. J. Org. Chem. 2005, 70, 2131.

(11) Yeom, H.-S.; Kim, S.; Shin, S. Synlett 2008, 924.

(12) Pagar, V. V.; Jadhav, A. M.; Liu, R.-S. J. Am. Chem. Soc. 2011, 133 , 20728.

(13) Shi, Z.; Koester, D. C.; Boultadakis-Arapinis, M.; Glorius, F. J. Am. Chem. Soc. 2013, 135, 12204.

(14) Lin, Y.-S.; Liu, C.-W.; Tsai, T. Y. R. Tetrahedron Lett. 2005, 46, 1859.

(15) (a) Ferguson, I. J.; Schofield, K. J. Chem. Soc., Perkin Trans. 11975 , 275. (b) Jasiński, M.; Mlostoń, G.; Linden, A.; Heimgartner, H. Helv. Chim. Acta 2008, 91, 1916. (c) Mlostoń, G.; Jasiński, M.; Heimgartner, H. Eur. J. Org. Chem. 2011, 2542.

(16) Shibata, Y.; Kagechika, K.; Yamaguchi, M.; Yoshikawa, K.; Chiba, K.; Takano, H.; Akiyama, C.; Ono, M.; Nishi, M.; Kubo, H.; Kobayashi, Y.; Usui, H. Chem. Pharm. Bull. 2013, 61, 1248.

(17) (a) Goto, Y.; Yamazaki, M.; Hamana, M. Chem. Pharm. Bull. 1971, 19, 2050. (b) Bénardeau, A.; Benz, J.; Binggeli, A.; Blum, D.; Boehringer, M.; Grether, U.; Hilpert, H.; Kuhn, B.; Märki, H. P.; Meyer, M.; Püntener, K.; Raab, S.; Ruf, A.; Schlatter, D.; Mohr, P. Bioorg. Med. Chem. Lett. 2009, 19, 2468.

(18) Luo, Y.-R. Handbook of Bond Dissociation Energies in Organic Compounds; CRC Press: Boca Raton, 2003.

(19) Eberbach, W.; Maier, W. Tetrahedron Lett. 1989, 30, 5591.

(20) (a) Zhang, L.; Sun, J.; Kozmin, S. A. Adv. Synth. Catal. 2006, 348, 2271. (b) Fürstner, A.; Davies, P. W. Angew. Chem. Int. Ed. 2007, 46, 3410. (c) Hashmi, A. S. K. Chem. Rev. 2007, 107, 3180. (d) Jiménez-Núñez, E.; Echavarren, A. M. Chem. Rev. 2008, 108, 3326. (e) Abu Sohel, S. M.; Liu, R.-S. Chem. Soc. Rev. 2009, 38, 2269.

(21) Ye, L.; Cui, L.; Zhang, G.; Zhang, L. J. Am. Chem. Soc. 2010, 132, 3258.

(22) Hashmi, A. S. K. Angew. Chem. Int. Ed. 2010, 49, 5232.

(23) Hashmi, A. S. K. Gold Bull. 2003, 36, 3.

(24) Cuenca, A. B.; Montserrai, S.; Hossain, K. M.; Mancha, G.; Lledos, A.; Medio-Simon, M.; Ujaque, G.; Asensio, G. Org. Lett. 2009, 11, 4906.

(25) Doyle, M. P.; McKervey, M. A.; Ye, T. Modern Catalytic Methods for Organic Synthesis with Diazo Compounds: From Cyclopropanes to Ylides; Wiley: New York, 1998.
(26) (a) Zhang, L. Acc. Chem. Res. 2014, 47, 877. (b) Lu, B.; Li, C.; Zhang, L. J. Am. Chem. Soc. 2010, 132, 14070. (c) Ye, L.; He, W.; Zhang, L. J. Am. Chem. Soc. 2010, 132, 8550. (d) Vasu, D.; Hung, H.-H.; Bhunia, S.; Gawade, S. A.; Das, A.; Liu, R.-S. Angew. Chem. Int. Ed. 2011, 50, 6911. (e) Hashmi, A. S. K.; Wang, T.; Shi, S.; Rudolph, M. J. Org. Chem. 2012, 77, 7761. (f) Wang, L.; Xie, X.; Liu, Y. Angew. Chem. Int. Ed. 2013, 52, 13302.

(27) Ji, K.; Nelson, J.; Zhang, L. Beilstein J. Org. Chem. 2013, 9, 1925.

(28) Bian, Z.; Marvin, C. C.; Martin, S. F. J. Am. Chem. Soc. 2013, 135, 10886.

(29) Kong, K.; Enquist, J. A.; McCallum, M. E.; Smith, G. M.; Matsumaru, T.; Menhaji-Klotz, E.; Wood, J. L. J. Am. Chem. Soc. 2013, 135, 10890.

(30) Luo, Y.; Ji, K.; Li, Y.; Zhang, L. J. Am. Chem. Soc. 2012, 134, 17412.

(31) He, W.; Xie, L.; Xu, Y.; Xiang, J.; Zhang, L. Org. Biomol. Chem. 2012, 10, 3168.

(32) Lundgren, R. J.; Peters, B. D.; Alsabeh, P. G.; Stradiotto, M. Angew. Chem. Int. Ed. 2010, 49, 4071.

(33) Bhunia, S.; Ghorpade, S.; Huple, D. B.; Liu, R.-S. Angew. Chem. Int. Ed. 2012, 51, 2939.

(34) Henrion, G.; Chavas, T. E. J.; Le Goff, X.; Gagosz, F. Angew. Chem. Int. Ed. 2013, 52, 6277.

(35) Huple, D. B.; Ghorpade, S.; Liu, R.-S. Chem. Eur. J. 2013, 19, 12965.

(36) Murai, M.; Kitabata, S.; Okamoto, K.; Ohe, K. Chem. Commun. 2012, 48, 7622.

(37) Liu, R.; Winston-McPherson, G. N.; Yang, Z.-Y.; Zhou, X.; Song, W.; Guzei, I. A.; Xu, X.; Tang, W. J. Am. Chem. Soc. 2013, 135, 8201.

(38) Sawama, Y.; Takubo, M.; Mori, S.; Monguchi, Y.; Sajiki, H. Eur. J. Org. Chem. 2011, 3361.

(39) Gronnier, C.; Kramer, S.; Odabachian, Y.; Gagosz, F. J. Am. Chem. Soc. 2012, 134, 828.

(40) Murahashi, S. Ruthenium in Organic Synthesis; Wiley-VCH: Weinheim, 2004.

(41) (a) Madhushaw, R. J.; Lin, M.-Y.; Sohel, S. M. A.; Liu, R.-S. J. Am. Chem. Soc. 2004, 126, 6895. (b) Lin, M.-Y.; Madhushaw, R. J.; Liu, R.-S. J. Org. Chem. 2004, 69, 7700. (c) Lin, M.-Y.; Maddirala, S. J.; Liu, R.-S. Org. Lett. 2005, 7, 1745. (d) Pati, K.; Liu, R.-S. Chem. Commun. 2009, 5233.

(42) Kim, I.; Lee, C. Angew. Chem. Int. Ed. 2013, 52, 10023.

(43) Cossío, F. P.; Arrieta, A.; Sierra, M. A. Acc. Chem. Res. 2008, 41, 925.

(44) Kim, I.; Roh, S. W.; Lee, D. G.; Lee, C. Org. Lett. 2014, 16, 2482.

(45) Wang, Y.; Zheng, Z.; Zhang, L. Angew. Chem. Int. Ed. 2014, 53, 9572.

(46) Chen, D.-F.; Han, Z.-Y.; He, Y.-P.; Yu, J.; Gong, L.-Z. Angew. Chem. Int. Ed. 2012, 51, 12307.

(47) Graf, K.; Rühl, C. L.; Rudolph, M.; Rominger, F.; Hashmi, A. S. K. Angew. Chem. Int. Ed. 2013, 52, 12727.

(48) Luo, Y.; Zhang, G.; Hwang, E. S.; Wilcoxon, T. A.; Zhang, L. Beilstein J. Org. Chem. 2011, 7, 596.

(49) (a) Barluenga, J.; Bernad, P. L. Jr.; Concellón, J. Tetrahedron Lett. 1995, 36, 3937. (b) Barluenga, J.; Fernández-Marí, F.; González, R.; Aguilar, E.; Revelli, G. A.; Viado, A. L.; Fañanás, F. J.; Olano, B. Eur. J. Org. Chem. 2000, 1773. (c) Barluenga, J.; García-Rodríguez, J.; Martínez, S.; Suárez-Sobrino, A. L.; Tomás, M. Chem. Eur. J. 2006, 12, 3201. (d) Barluenga, J.; Martínez, S.; Suárez-Sobrino, A. L.; Tomás, M. Organometallics 2006, 25, 2337. (e) Luo, N.; Zheng, Z.; Yu, Z. Org. Lett. 2011, 13, 3384. (f) Zheng, Z.; Chen, J.; Luo, N.; Yu, Z.; Han, X. Organometallics 2006, 25, 5301. (g) Zheng, Z.; Yu, Z.; Luo, N.; Han, X. J. Org. Chem. 2006, 71, 9695. 
(50) (a) Alcázar, J.; Alonso, J. M.; Bartolomé, J. M.; Iturrino, L.; Matesanz, E. Tetrahedron Lett. 2003, 44, 8983. (b) Yoo, E.; Crall, B. M.; Balakrishna, R.; Malladi, S. S.; Fox, L. M.; Hermanson, A. R.; David, S. A. Org. Biomol. Chem. 2013, 11, 6526. (c) De Schutter, J. W.; Shaw, J.; Lin, Y.-S.; Tsantrizos, Y. S. Bioorg. Med. Chem. 2012, 20, 5583. (d) Londregan, A. T.; Jennings, S.; Wei, L. Org. Lett. 2010, 12, 5254. (e) Yin, J.; Xiang, B.; Huffman, M. A.; Raab, C. E.; Davies, I. W. J. Org. Chem. 2007, 72, 4554. (f) Manley, P. J.; Bilodeau, M. T. Org. Lett. 2002, 4, 3127. (g) Chen, X.; Li, X.; Qu, Z.; Ke, D.; Qu, L.; Duan, L.; Mai, W.; Yuan, J.; Chen, J.; Zhao, Y. Adv. Synth. Catal. 2014, 356, 1979. (h) Couturier, M.; Caron, L.; Tumidajski, S.; Jones, K.; White, T. D. Org. Lett. 2006, 8, 1929. (i) Londregan, A. T.; Jennings, S.; Wei, L. Org. Lett. 2011, 13, 1840. (j) Medley, J. W.; Movassaghi, M. J. Org. Chem. 2008, 74, 1341. (k) Kokatla, H. P.; Yoo, E.; Salunke, D. B.; Sil, D.; Ng, C. F.; Balakrishna, R.; Malladi, S. S.; Fox, L. M.; David, S. A. Org. Biomol. Chem. 2013, 11, 1179. (1) Ichihara, Y.; Fujimura, R.; Tsuneki, H.; Wada, T.; Okamoto, K.; Gouda, H.; Hirono, S.; Sugimoto, K.; Matsuya, Y.; Sasaoka, T.; Toyooka, N. Eur. J. Med. Chem. 2013, 62, 649. (m) Farrell, R. P.; Silva Elipe, M. V.; Bartberger, M. D.; Tedrow, J. S.; Vounatsos, F. Org. Lett. 2013, 15, 168. (n) Eskildsen, J.; Vedsø, P.; Begtrup, M. Synthesis 2001, 1053.

(51) Abramovitch, R. A.; Singer, G. M. J. Am. Chem. Soc. 1969, 91, 5672.

(52) Kellogg, R. M.; Van Bergen, T. J.J. Org. Chem. 1971, 36, 1705.

(53) Andersson, H.; Olsson, R.; Almqvist, F. Org. Biomol. Chem. 2011, $9,337$.

(54) Andersson, H.; Sainte-Luce Banchelin, T.; Das, S.; Olsson, R.; Almqvist, F. Chem. Commun. 2010, 46, 3384.

(55) Zhang, S.; Liao, L.-Y.; Zhang, F.; Duan, X.-F. J. Org. Chem. 2013, $78,2720$.

(56) Hussain, M.; Banchelin, T. S.-L.; Andersson, H.; Olsson, R.; Almqvist, F. Org. Lett. 2013, 15, 54.

(57) Larionov, O. V.; Stephens, D.; Mfuh, A.; Chavez, G. Org. Lett. 2014, 16, 864.

(58) Araki, Y.; Kobayashi, K.; Yonemoto, M.; Kondo, Y. Org. Biomol. Chem. 2011, 9, 78.
(59) (a) Campeau, L.-C.; Schipper, D. J.; Fagnou, K. J. Am. Chem. Soc. 2008, 130, 3266. (b) Campeau, L.-C.; Bertrand-Laperle, M.; Leclerc, J.-P.; Villemure, E.; Gorelsky, S.; Fagnou, K. J. Am. Chem. Soc. 2008, 130, 3276. (c) Campeau, L.-C.; Rousseaux, S.; Fagnou, K. J. Am. Chem. Soc. 2005, 127, 18020. (d) Huestis, M. P.; Fagnou, K. Org. Lett. 2009, 11, 1357. (e) Schipper, D. J.; Campeau, L.-C.; Fagnou, K. Tetrahedron 2009, 65, 3155. (f) Sun, H.-Y.; Gorelsky, S. I.; Stuart, D. R.; Campeau, L.-C.; Fagnou, K.J. Org. Chem. 2010, 75, 8180. (g) Tan, Y.; Barrios-Landeros, F.; Hartwig, J. F. J. Am. Chem. Soc. 2012, 134, 3683.

(60) Xiao, B.; Liu, Z.-J.; Liu, L.; Fu, Y.J. Am. Chem. Soc. 2013, 135, 616.

(61) Wu, Z.; Song, H.; Cui, X.; Pi, C.; Du, W.; Wu, Y. Org. Lett. 2013, 15, 1270.

(62) Cho, S. H.; Hwang, S. J.; Chang, S. J. Am. Chem. Soc. 2008, 130, 9254.

(63) (a) Liu, W.; Li, Y.; Xu, B.; Kuang, C. Org. Lett. 2013, 15, 2342. (b) Liu, W.; Li, Y.; Wang, Y.; Kuang, C. Org. Lett. 2013, 15, 4682.

(64) Wu, Z.; Pi, C.; Cui, X.; Bai, J.; Wu, Y. Adv. Synth. Catal. 2013, 355, 1971.

(65) Li, G.; Jia, C.; Sun, K. Org. Lett. 2013, 15, 5198.

(66) Zhu, C.; Yi, M.; Wei, D.; Chen, X.; Wu, Y.; Cui, X. Org. Lett. 2014, $16,1840$.

(67) Kanyiva, K. S.; Nakao, Y.; Hiyama, T. Angew. Chem. Int. Ed. 2007, $46,8872$.

(68) Chen, X.; Zhu, C.; Cui, X.; Wu, Y. Chem. Commun. 2013, 49, 6900.

(69) Shibata, T.; Matsuo, Y. Adv. Synth. Catal. 2014, 356, 1516.

(70) Hwang, H.; Kim, J.; Jeong, J.; Chang, S. J. Am. Chem. Soc. 2014, 136, 10770.

(71) Jeong, J.; Patel, P.; Hwang, H.; Chang, S. Org. Lett. 2014, 16, 4598.

(72) (a) Heaney, F.; Lawless, E.; Mahon, M.; McArdle, P.; Cunningham, D. Org. Biomol. Chem. 2006, 4, 2408. (b) Holt, J.; Fiksdahl, A. J. Heterocycl. Chem. 2007, 44, 375. (c) Raminelli, C.; Liu, Z.; Larock, R. C. J. Org. Chem. 2006, 71, 4689. (d) Shaibu, B. S.; Kawade, R. K.; Liu, R.-S. Org. Biomol. Chem. 2012, 10, 6834. (e) Loska, R.; Mąkosza, M. Mendeleev Commun. 2006, 16, 161. (f) Loska, R.; Mąkosza, M. Chem. Eur. J. 2008, 14, 2577. (g) Loska, R.; Szachowicz, K.; Szydlik, D. Org. Lett. 2013, 15, 5706. 